\title{
Indo-Western Pacific Climate Variability: ENSO Forcing and Internal Dynamics in a Tropical Pacific Pacemaker Simulation
}

\author{
CHUAN-YANG WANG \\ Physical Oceanography Laboratory/Qingdao Collaborative Innovation Center of Marine Science and Technology, \\ Ocean University of China and Qingdao National Laboratory for Marine Science and Technology, Qingdao, China, \\ and Scripps Institution of Oceanography, University of California at San Diego, La Jolla, California

\section{SHANG-PING XIE} \\ Scripps Institution of Oceanography, University of California at San Diego, La Jolla, California, and Physical Oceanography \\ Laboratory/Qingdao Collaborative Innovation Center of Marine Science and Technology, Ocean University of China and \\ Qingdao National Laboratory for Marine Science and Technology, Qingdao, China \\ YU KOSAKA \\ Research Center for Advanced Science and Technology, University of Tokyo, Tokyo, Japan
}

(Manuscript received 5 April 2018, in final form 21 August 2018)

\begin{abstract}
El Niño-Southern Oscillation (ENSO) peaks in boreal winter but its impact on Indo-western Pacific climate persists for another two seasons. Key ocean-atmosphere interaction processes for the ENSO effect are investigated using the Pacific Ocean-Global Atmosphere (POGA) experiment with a coupled general circulation model, where tropical Pacific sea surface temperature (SST) anomalies are restored to follow observations while the atmosphere and oceans are fully coupled elsewhere. The POGA shows skills in simulating the ENSO-forced warming of the tropical Indian Ocean and an anomalous anticyclonic circulation pattern over the northwestern tropical Pacific in the post-El Niño spring and summer. The 10-member POGA ensemble allows decomposing Indo-western Pacific variability into the ENSO forced and ENSO-unrelated (internal) components. Internal variability is comparable to the ENSO forcing in magnitude and independent of ENSO amplitude and phase. Random internal variability causes apparent decadal modulations of ENSO correlations over the Indo-western Pacific, which are high during epochs of high ENSO variance. This is broadly consistent with instrumental observations over the past 130 years as documented in recent studies. Internal variability features a sea level pressure pattern that extends into the north Indian Ocean and is associated with coherent SST anomalies from the Arabian Sea to the western Pacific, suggestive of ocean-atmosphere coupling.
\end{abstract}

\section{Introduction}

El Niño-Southern Oscillation (ENSO) is the major mode of interannual variability and a key driver for global climate variability (e.g., Alexander et al. 2002). ENSO develops in summer [JJA(0)], peaks in winter $[\operatorname{NDJ}(0 / 1)]$, and decays rapidly in the following spring [MAM(1)], where JJA is June-August, NDJ is NovemberJanuary, and MAM is March-May. The numerals denote the ENSO developing (0) and decay (1) years, respectively. Seasons refer to those of the Northern Hemisphere.

\footnotetext{
Corresponding author: Shang-Ping Xie, sxie@ucsd.edu
}

While the anomalous SST over the eastern tropical Pacific diminishes by JJA(1), the ENSO effect on the Indowestern Pacific region remains prominent, manifested as the basinwide warming in the Indian Ocean (IO) and a low-level anomalous anticyclone (AAC) over the tropical northwestern Pacific (NWP).

The basinwide IO warming develops gradually with El Niño, peaks at MAM(1), and persists to the following summer (Nigam and Shen 1993; Liu and Alexander 2007; Schott et al. 2009; Du et al. 2009). ENSO alters atmospheric circulation and convection over the tropical IO (TIO) via the atmospheric bridge (Alexander et al. 2002; Liu and Alexander 2007), inducing anomalous 
surface heat fluxes to warm the tropical IO (Klein et al. 1999). Surface heat fluxes, although appearing to be important in winter (Wu and Yeh 2010), cannot explain the tropical southwestern IO (SWIO) warming in spring (Klein et al.1999), suggesting the role of ocean dynamics in this region. During the developing and mature phase of El Niño, an anomalous anticyclone forms over the southeastern tropical IO, which induces downwelling ocean Rossby waves propagating westward (Perigaud and Delecluse 1993; Masumoto and Meyers 1998). In spring, the Rossby wave reaches the SWIO where the thermocline is shallow (Xie et al. 2002), inducing surface warming through thermocline feedback (Du et al. 2009; Xie et al. 2010). An ocean barrier layer co-propagating with the Rossby wave may also help sustain the warm SST (Chowdary et al. 2009). The SWIO warming induces an antisymmetric anomaly pattern with northeasterlies (northwesterlies) and suppressed (enhanced) precipitation north (south) of the equator in spring (Wu et al. 2008; Du et al. 2009; Chakravorty et al. 2013). This antisymmetric pattern warms the north IO (NIO) in the following summer by reducing the mean southwesterlies and increasing shortwave radiation (Du et al. 2009; Wu and Yeh. 2010).

Over the NWP, a low-level AAC develops in fall and winter (Zhang et al. 1996; Wu et al. 2003) in response to ENSO (Wang et al. 2000; Li et al. 2017). The northeasterlies on the southeastern flank of the AAC cool the ocean by strengthening the background trade winds. Negative SST anomalies suppress local convection and enhance the AAC with a Rossby wave response. This local positive wind-evaporation-SST (WES) feedback helps the AAC to persist (Wang et al. 2003, 2017), for which the background northeasterly trade winds are essential. When the trade winds retreat eastward in summer, the AAC becomes coupled with IO SST. Positive IO SST anomalies excite a Matsuno-Gill pattern (Matsuno 1966; Gill 1980) to support the AAC via a Kelvin wave-induced Ekman divergence mechanism (Terao and Kubota 2005; Xie et al. 2009). The anomalous easterlies on the south flank of the AAC extend to the NIO, weaken the background southwesterly monsoon, and warm the SST. The warm IO SST and NWP AAC then form an interbasin positive feedback (Kosaka et al. 2013; Xie et al. 2016).

The Indo-western Pacific Ocean capacitor (IPOC) mode refers to the above coherent variabilities of coupled anomalies over the tropical IO and NWP in the post-El Niño summer (Xie et al. 2016; Xie and Zhou 2017). The IO SST and NWP AAC develop separately in winter and spring following the peak of El Niño and become coupled together in summer, resulting in regional positive feedbacks.
The correlations between IPOC and equatorial Pacific SST show strong multidecadal variations (e.g., $\mathrm{Wu}$ and Wang 2002; Wang et al. 2008). The decadal modulation of ENSO amplitude appears to be a major factor. Chowdary et al. (2012) show that correlations between NIO SST and preceding winter ENSO have covaried with ENSO amplitude over the past 130 years. Kubota et al. (2016) find a similar relationship between ENSO and the Pacific-Japan (PJ) pattern (Nitta 1986; Kosaka and Nakamura 2006), whose tropical lobe corresponds to the low-level AAC of the IPOC mode. Similar slow modulations are captured in coupled models (e.g., Du et al. 2013; Hu et al. 2014). Non-ENSO factors may also modulate the ENSO-IPOC relationship, such as the shoaling thermocline ridge in the SWIO after the 1970s (Xie et al. 2010) and the mean subtropical high change over the NWP associated with the interdecadal Pacific oscillation (Song and Zhou 2015).

There is growing evidence for the ENSO-unrelated variability in Indo-western Pacific climate. Using a partially coupled general circulation model (GCM), Huang and Shukla (2007b) show that Indian Ocean SST and heat content display strong interannual variability without ENSO. Zhou et al. (2018) report that atmospheric GCM rainfall variability, regionally enhanced over the NIO and NWP and unrelated to SST anywhere, is likely to be associated with internal atmospheric variability. Kosaka et al. (2013) detect the summer IPOC mode, due to interbasin positive feedback, in a coupled GCM experiment where ENSO is artificially suppressed.

From observations, it is difficult to separate ENSOforced and ENSO-unrelated variability (hereafter called internal variability). Global satellite observations cover the most recent 40 years or less, marginal for analysis of multidecadal variability. Shipboard and station observations offer longer records, but the coverage and accuracy deteriorate further back in time (e.g., Wu et al. 2005; Tokinaga et al. 2012). Coupled models often suffer from large biases in ENSO simulation (Bellenger et al. 2014). Previous Pacific pacemaker experiments mainly focused on the ensemble mean (e.g., Lau and Nath 2000, 2003; Huang and Shukla 2007a,b; Kamae et al. 2017; Wu et al. 2017a,b), while intermember variability in Indo-western Pacific climate remains poorly explored.

The present study examines the ENSO-forced and internal variabilities in the Indo-western Pacific region using a 10-member ensemble of the Pacific OceanGlobal Atmosphere (POGA) experiment, where monthly SST anomalies in the tropical Pacific are restored toward observations. The realistic evolution of ENSO allows direct comparison of ENSO effects with observations. The POGA experiment has been used to study the global 
warming hiatus (Kosaka and Xie 2013, 2016) and regional climate variability (Yang et al. 2015, 2017). We start by comparing the POGA ensemble mean with observations. The POGA shows high skill in simulating coupled processes in post-El Niño seasons in the Indowestern Pacific region. We show that internal variability is comparable in magnitude with the ENSO-forced counterpart and can explain multidecadal modulations of ENSO correlations in the Indo-western Pacific, much as in observations. Our results suggest a role of regional ocean-atmosphere coupling in the internal variability.

The rest of the paper is organized as follows. Section 2 describes the data and methods. Section 3 analyzes the skills of POGA experiment in simulating the IPOC mode. Section 4 examines the ENSO-forced and internal variability over the Indo-western Pacific. Section 4 also discusses how these variabilities cause multidecadal modulation of ENSO correlations. Section 5 summarizes and discusses our results.

\section{Data and methods}

We analyze the output of POGA experiments [see Kosaka and Xie (2016) for a detailed description of the experiment] based on the Geophysical Fluid Dynamics Laboratory (GFDL) coupled model version 2.1 (GFDLCM2.1, hereafter CM2.1; Delworth et al. 2006). The CM2.1 POGA ensemble consists of 10 members. Each member covers the period of 1861-2014, starting with different initial conditions but forced with the same radiative forcing. Over the eastern tropical Pacific $\left(15^{\circ} \mathrm{S}_{-}\right.$ $15^{\circ} \mathrm{N}$, date line to the American coast, with a $5^{\circ}$ buffer zone), SST is restored to follow the observed anomalies while the ocean and atmosphere are fully coupled elsewhere. The first 10 years are discarded as the spinup.

We use the raw output of each realization, the ensemble mean, and the intermember spread of POGA. The intermember spread of one realization is obtained by subtracting the ensemble mean from its corresponding raw output. As the 10 members share the same external forcing and tropical eastern Pacific SST variability (mostly ENSO), we use the ensemble mean to represent the ENSO-forced variability. The intermember spread captures internal variability as different initial conditions of each ensemble member randomize the phasing of internal variability. Similar approaches have been utilized to analyze the Indian Ocean dipole mode and tropical Atlantic variabilities (Yang et al. 2015, 2017).

To compare with observations, we use precipitation, $850-\mathrm{hPa}$ winds, tropospheric temperature averaged between 300 and $850 \mathrm{hPa}$, and sea level pressure data from the National Centers for Environmental Prediction
(NCEP)-National Center for Atmospheric Research (NCAR) reanalysis (Kalnay et al. 1996). We analyze the SST and sea surface height (SSH) data from the Extended Reconstructed Sea Surface Temperature, version 4 (ERSST v4; Huang et al. 2015), and Simple Ocean Data Assimilation reanalysis, version 2.2.4 (SODA v2.2.4; Giese and Ray 2011), respectively.

All variables from both POGA and observations are interpolated onto a common $1^{\circ} \times 1^{\circ}$ grid. An 11-point Lanczos high-pass filter with half-power at 11 years is applied on all variables at each grid point to remove decadal variability and long-term trends for both the model and observations. The maximum common period (1948-2014) is used in the comparison between the POGA and observations in section 3 while the entire output period is analyzed to study the interactions between the ENSO-forced and internal variabilities.

\section{ENSO-forced IPOC}

\section{a. Persistent $I O$ warming}

We start by comparing the seasonal evolution of Indian Ocean correlations (Figs. 1a,b) with the NDJ(0/1) Niño-3.4 index between observations and the POGA ensemble mean during 1948-2014. The Niño-3.4 index is defined as SST anomalies averaged over the central to eastern tropical Pacific $\left(5^{\circ} \mathrm{S}-5^{\circ} \mathrm{N}, 170^{\circ}-120^{\circ} \mathrm{W}\right)$. The POGA captures the tropical IO $\left(20^{\circ} \mathrm{S}-20^{\circ} \mathrm{N}, 40^{\circ}-100^{\circ} \mathrm{E}\right)$ warming in the mature and decay phases of El Niño. In observations, positive SST anomalies in the tropical IO emerge late in the ENSO developing summer, peak in the next spring, and then decay slowly during the following summer. In POGA, tropical IO SST begins to warm late in September-November $[\mathrm{SON}(0)]$ and develops rapidly in the following winter. The delayed warming in the tropical IO, compared to observations, is possibly due to cold SST biases in the NIO (not shown). The correlation coefficient between IO SST and ENSO then remains high for the next two seasons, and finally drops rapidly in August-October [ASO(1)]. In the POGA ensemble mean, the NIO SST $\left(0^{\circ}-20^{\circ} \mathrm{N}\right.$, $\left.40^{\circ}-100^{\circ} \mathrm{E}\right)$ displays a double-peak pattern with the maximum correlation at $\mathrm{NDJ}(0 / 1)$ and JJA(1). In observations, the double-peak structure is weak for 19482014 but strengthens if we limit the analysis to after the 1970s regime shift (not shown), potentially due to decadal modulations of ENSO variability and the IO background state (e.g., Huang et al. 2010; Xie et al. 2010). Such interdecadal modulations are weak in the POGA ensemble mean where the internal variability is suppressed. This indicates the potential role of internal variability in the interdecadal modulation of ENSO-IO 

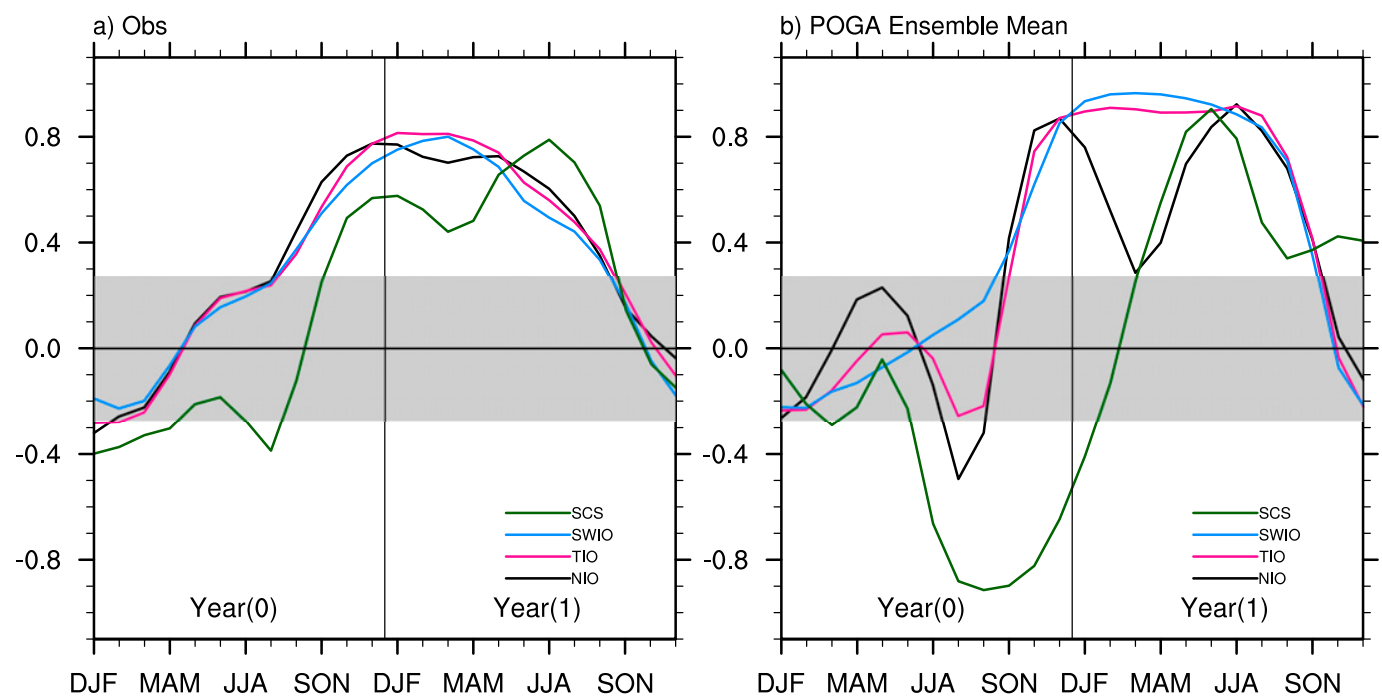

FIG. 1. Seasonal evolution of correlation coefficients of the SCS $\left(0^{\circ}-20^{\circ} \mathrm{N}, 100^{\circ}-120^{\circ} \mathrm{E}\right)$, SWIO $\left(5^{\circ}-15^{\circ} \mathrm{S}, 40^{\circ}-\right.$ $\left.80^{\circ} \mathrm{E}\right)$, TIO $\left(20^{\circ} \mathrm{S}-20^{\circ} \mathrm{N}, 40^{\circ}-100^{\circ} \mathrm{E}\right)$, and NIO $\left(5^{\circ}-20^{\circ} \mathrm{N}, 40^{\circ}-100^{\circ} \mathrm{E}\right)$ SST with the NDJ $(0 / 1)$ Niño- 3.4 index in (a) observations and (b) the POGA ensemble mean. Correlation coefficients below the 0.01 significance level based on a Student's $t$ test are shaded.

SST correlations. The interdecadal modulation of the ENSO-IPOC correlation is discussed in section 4. Tropical SWIO $\left(5^{\circ}-15^{\circ} \mathrm{S}, 40^{\circ}-80^{\circ} \mathrm{E}\right)$ SST correlation with ENSO shows a similar pattern to the tropical IO in observations and the POGA ensemble mean. SWIO SST variability in the POGA ensemble mean shows consistent evolution with observations in the El Niño fall and winter. South China Sea (SCS; $5^{\circ}-20^{\circ} \mathrm{N}, 100^{\circ}-$ $\left.120^{\circ} \mathrm{E}\right) \mathrm{SST}$ shows the largest bias in the POGA ensemble mean. In El Niño fall and winter, POGA fails to simulate the SST warming and instead produces a strong cooling, which may be associated with biased southwesterly anomalies developed in JJA(0) (not shown). The anomalous southwesterlies intensify the background southwesterly summer monsoon and cools the SST with enhanced evaporation. Model biases in simulating the winter monsoon may also contribute to SST bias in winter (Wu et al. 2014). SCS SST begins to warm up quickly in SON(0) due to increased surface heat flux (not shown) and peaks at May-July [MJJ(1)].

The regional mean IO SST regressions against the Niño-3.4 index generally follow the evolution of the correlations (not shown). Figure 2 shows the spatial distribution of SST and 850 -hPa winds regression coefficients against the Niño-3.4 index. Both observations and POGA show strong positive SST anomalies over the equatorial and central southern tropical IO in El Niño winter $[\mathrm{DJF}(0 / 1)]$, accompanied with an anticyclonic wind circulation over the southern tropical IO. The POGA shows some cold biases in the NIO and SCS. Apart from the bias in the SCS discussed above, there is another cool SST band north of the equator, which may be related to the large evaporative cooling induced by easterly anomalies in SON(0) (not shown). In MAM(1), the POGA shows a larger cross-equatorial SST gradient with stronger (weaker) warming south (north) of the equator than observations. Increased cross-equatorial SST gradient induces an enhanced antisymmetric wind pattern (Figs. 2c,d) that cools the NIO and warms the south IO (Wu et al. 2008). In JJA(1), the POGA captures the three major warming centers over the SCS, Arabian Sea, and SWIO but with somewhat large amplitudes compared to observations. Enhanced SST anomalies in the NIO may be associated with the strong antisymmetric wind pattern in the previous season. POGA displays a strong warming signal off the west coast of the Arabian Sea associated with anomalous northeasterlies. The anomalous northeasterlies over the western Arabian Sea may also induce in-shore Ekman transport and further warm the SST by suppressing coastal upwelling (Izumo et al. 2008). In all three seasons, the SST and circulation anomalies are stronger in POGA than in observations, indicating an overestimation of ENSO teleconnection. Overall, the CM2.1 POGA shows a good skill in simulating El Niño-induced IO warming.

The SWIO SST anomalies play a crucial role in anchoring the asymmetric winds and warming the NIO in summer. The NIO warming in the El Niño decay summer is often referred to as the "second warming" (Du et al.2009). Figure 3 shows the time-longitude section of the regression coefficient of tropical south IO $\left(15^{\circ}-5^{\circ} \mathrm{S}\right)$ 


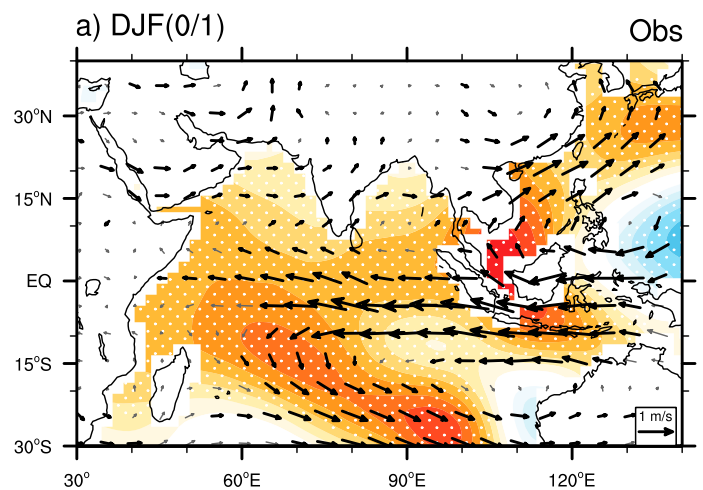

c) $\operatorname{MAM}(1)$
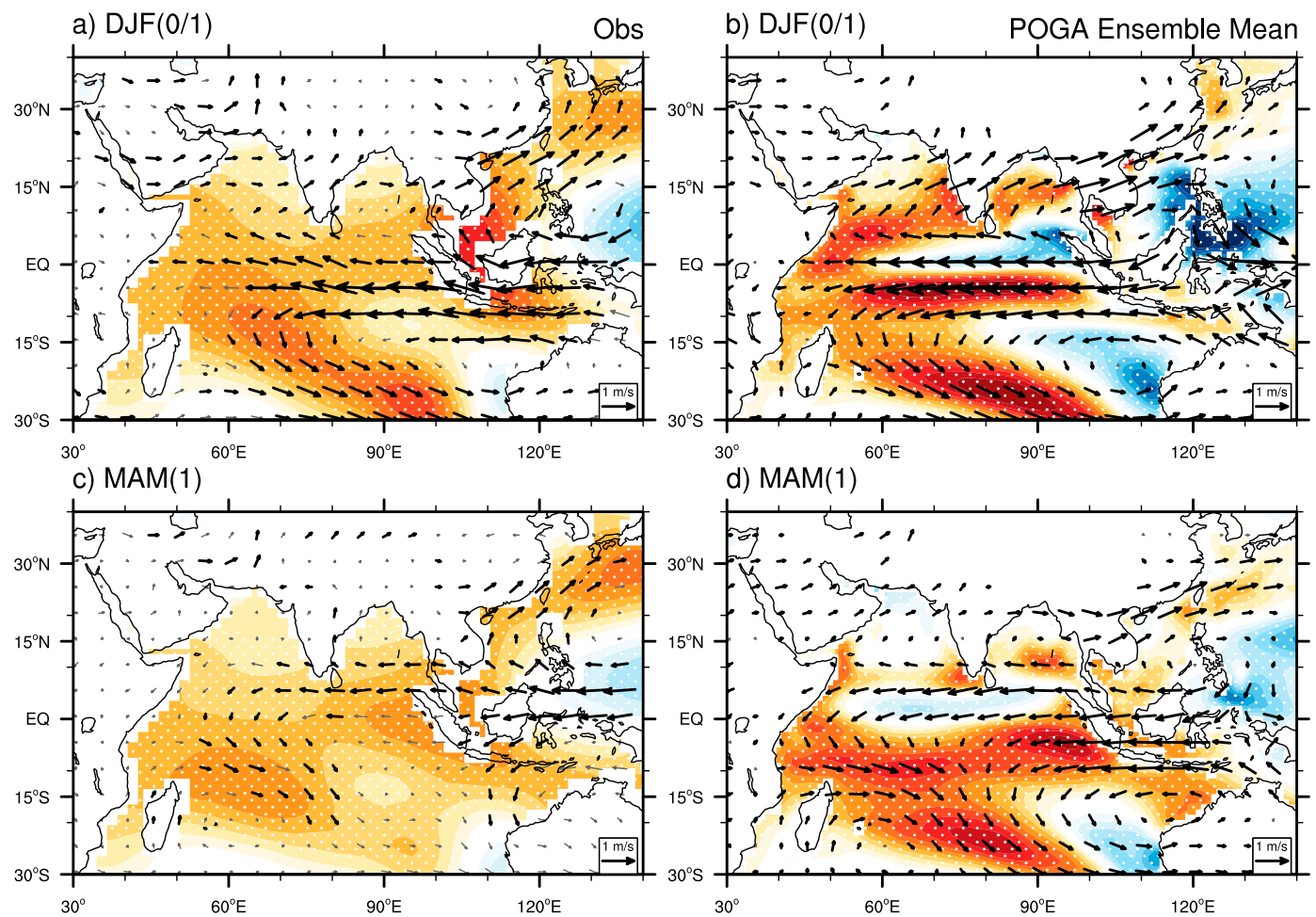

d) $\operatorname{MAM}(1)$
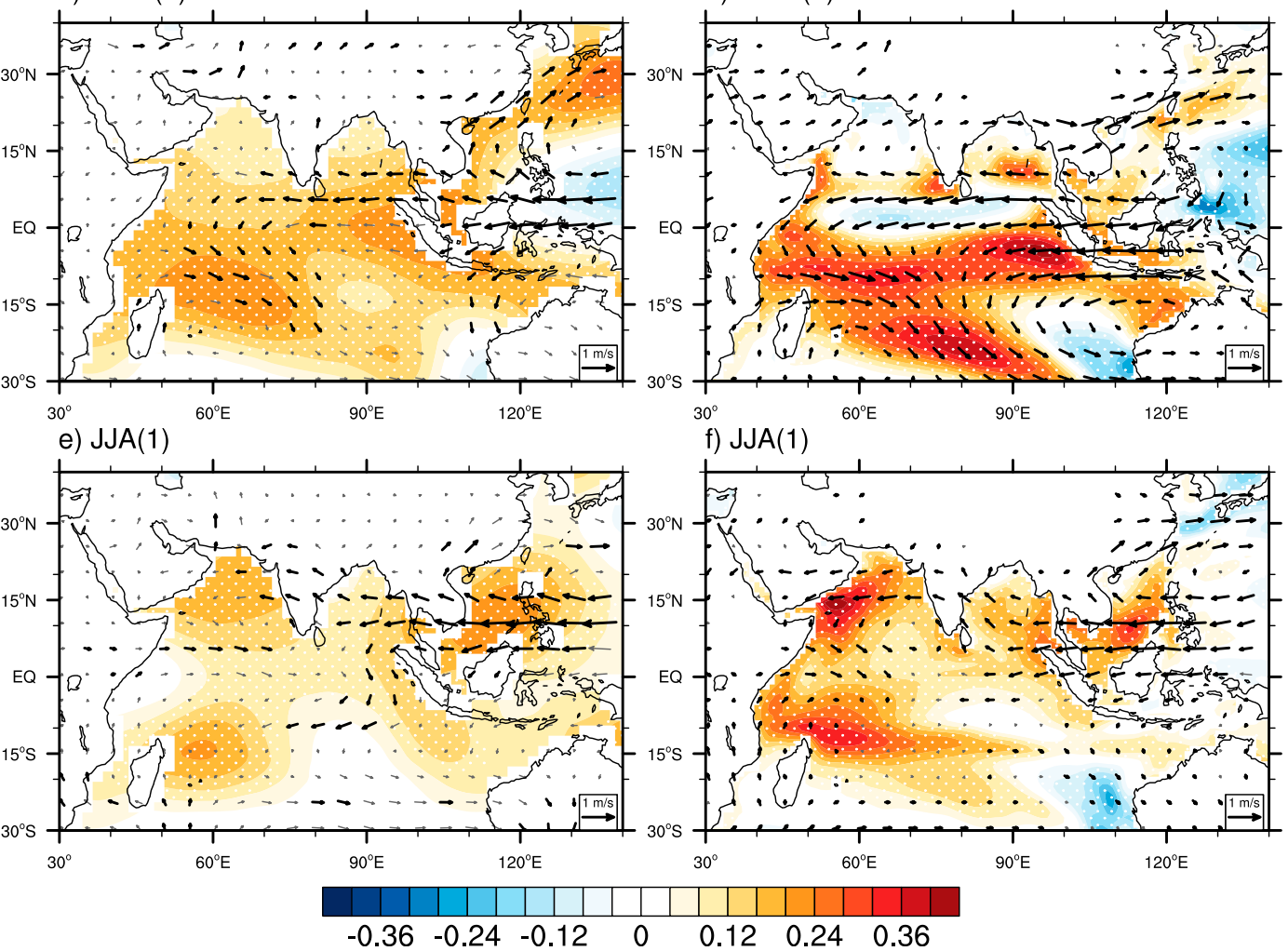

FIG. 2. Seasonal evolution of the regression coefficient of the IO SST (shading; $\mathrm{K} \mathrm{K}^{-1}$ ) and 850-hPa winds (arrows) against the NDJ(0/1) Niño-3.4 index in (a),(c),(e) observations and (b),(d),(f) the POGA ensemble mean. SST and winds (either zonal or meridional) whose correlation exceeds the 0.01 significance level based on a Student's $t$ test are stippled and thickened, respectively.

SST and SSH against the Niño-3.4 index. POGA captures the westward co-propagating SST and SSH signals associated with the oceanic Rossby waves. Positive SSH in the tropical SWIO and the accompanying positive SST in the POGA delay by one season compared to observations. This is due to the weak anticyclonic circulation over the tropical south IO in SON(0). The delayed SST warming in the tropical SWIO also prolongs the second warming peak in the NIO (Fig. 1). The $\mathrm{SSH}$ anomalies are wider in the zonal direction as the local wind stress forcing is strong and shifted westward compared to observations (not shown). Such bias is common in CMIP5 models (Du et al. 2013).

\section{b. Evolution of the anomalous anticyclone}

This section evaluates the skill of POGA in simulating the anomalous anticyclone over the NWP in the postENSO spring and summer. We compute the joint empirical orthogonal function (EOF) of MAM and JJA sea level pressure (SLP) variability over the NWP region $\left(10^{\circ}-40^{\circ} \mathrm{N}, 100^{\circ}-160^{\circ} \mathrm{E}\right.$; purple boxes in Figs. $\left.4 \mathrm{c}, \mathrm{e}\right)$ for each of the POGA ensemble mean and observations. 


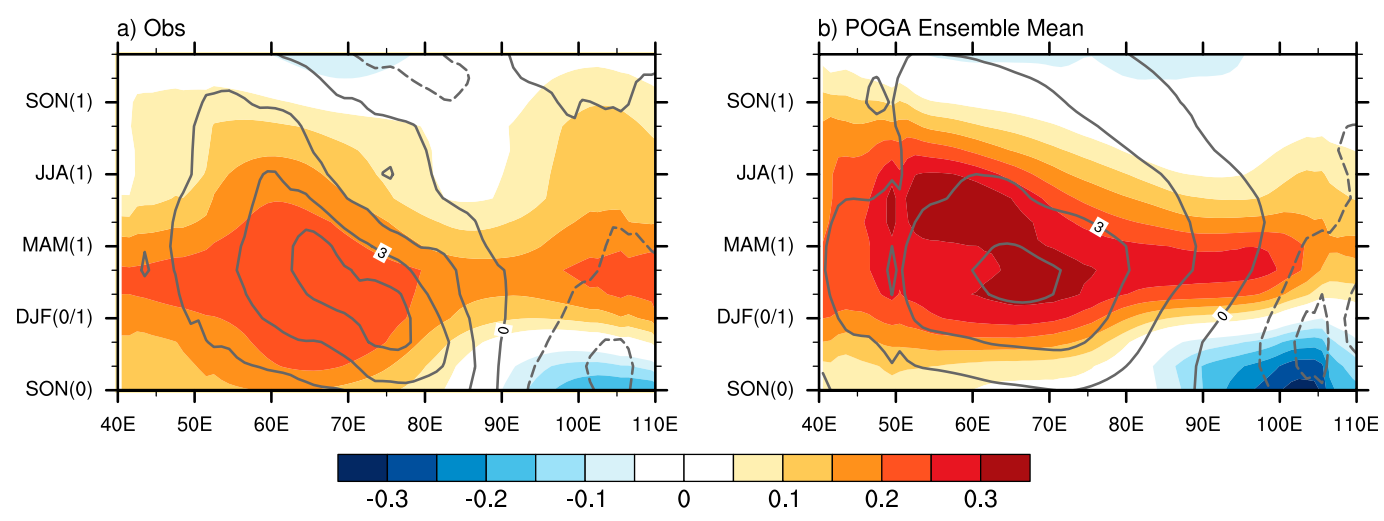

FIG. 3. Time-longitude section of the regression coefficients of tropical south IO $\left(15^{\circ}-5^{\circ} \mathrm{S}\right) \mathrm{SST}$ (shading; $\mathrm{K} \mathrm{K}^{-1}$ ) and SSH (contours with interval of $1.5 \mathrm{~cm} \mathrm{~K}^{-1}$ ) against the Niño-3.4 index from fall of year (0) through year (1) in (a) observations and (b) the POGA ensemble mean.

The seasonally stratified EOF analysis yields two spatial patterns for MAM and JJA, respectively, accompanied by a common principal component (PC).

Figures 4 and 5 compare the regression coefficients of SST, SLP, 850-hPa winds, precipitation, and tropospheric temperature (TT) averaged between 300 and $850 \mathrm{hPa}$ against the leading PCs (PC1s) between the observations and POGA ensemble mean. In the observations, the AAC forms in fall and winter over the SCS and moves eastward of the Philippines in winter, coupled with cold SST anomalies on its southeast flank (Fig. 4a). The anomalous northeasterlies cool the ocean by enhancing the background northeasterly winds, while cold SST suppresses local atmospheric convection and excites the AAC as a Rossby wave response (Wang et al. 2000). The POGA ensemble mean captures the AAC, but the center of the AAC is slightly displaced west over the SCS (Figs. 4a,b). The SST and precipitation patterns resemble observations but show similar westward displacements (Figs. 5a,b). In the following spring, the AAC extends northeastward in both observations and POGA (Figs. 4c,d). Over the NWP, cold SST collocates with suppressed precipitation, indicating a strong local coupling (Figs. 5c,d). The POGA also captures the cross-equatorial antisymmetric circulation and precipitation pattern in MAM. The amplitudes of the anomalies are large compared to observations (Figs. 5c,d), consistent with our results on IO response (Fig. 2). In summer, the cold SST on the southeast flank of the AAC weakens, and the AAC is anchored by the warm SST over the NIO (Figs. 4e,f). Warm SST enhances precipitation over the IO and Maritime Continent and excites a Matsuno-Gill pattern (Figs. 5e,f). With the friction, the Kelvin wave induces the low-level divergence that sustains the AAC north of the equator (Xie et al. 2009). The anomalous northeasterlies over the NIO and SCS warm SST by reducing the prevailing southwesterly monsoon and evaporation (Figs. 4e,f; Kosaka et al. 2013).

The correlation coefficient between the observed and ensemble mean PC1 is 0.62 . The correlation coefficients of the two PC1s against the preceding NDJ Niño-3.4 index are 0.59 and 0.90 for observations and the POGA ensemble mean, respectively. We have performed a similar EOF analysis in each POGA member. The correlations between the leading PC and preceding Niño3.4 index in individual runs range from 0.47 to 0.66 , comparable to that of the observations but smaller than the ensemble mean. The higher correlation in the ensemble mean is due to the suppressed ENSO-unrelated variability. Significant correlations in the individual runs and observations confirm ENSO's role in driving Indowestern Pacific climate anomalies.

POGA shows some biases in simulating the NWP circulations. For example, the center of the anomalous high surface pressure and accompanying AAC in POGA is displaced west compared to observations in DJF and MAM (Fig. 4, top two panels). This may be related to the forcing of the westward-shifted El Niño warming center over the equatorial Pacific Ocean, due to a common equatorial Pacific cold tongue bias among CMIP5 models (Du et al. 2013; Li and Xie 2014). This bias is alleviated in summer, as the AAC is coupled with warm SST in the Indian Ocean.

The Indo-western Pacific region not only passively responds to ENSO but also shows strong local oceanatmospheric coupling (Kosaka et al. 2013, Xie et al. 2016). ENSO-induced SST anomalies persist through summer and anchor atmospheric anomalies such as AAC when ENSO itself has dissipated. The correlation coefficients between JJA NIO, including SCS, SST $\left(0^{\circ}-20^{\circ} \mathrm{N}, 40^{\circ}-120^{\circ} \mathrm{E}\right)$, and $\mathrm{PC} 1$ are 0.62 and 0.89 in 
a) DJF

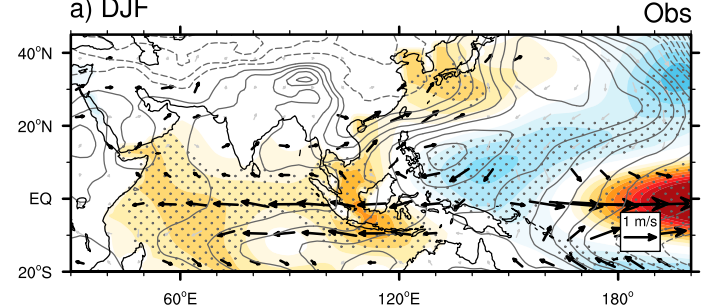

c) MAM

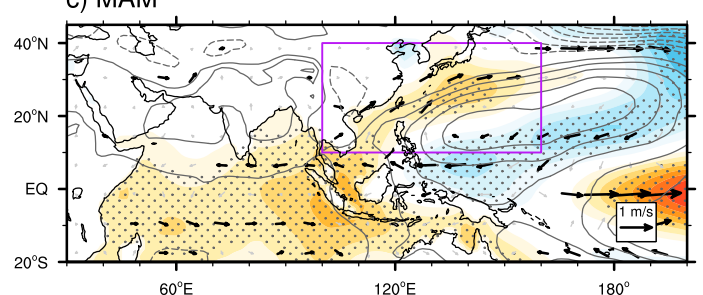

e) JJA

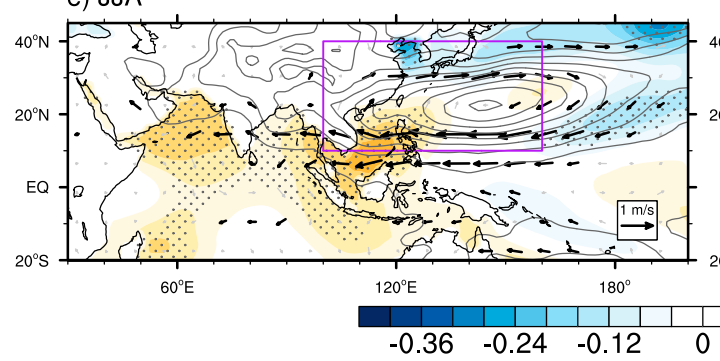

g) $\mathrm{PC} 1 \mathrm{r}=0.62$ b) DJF

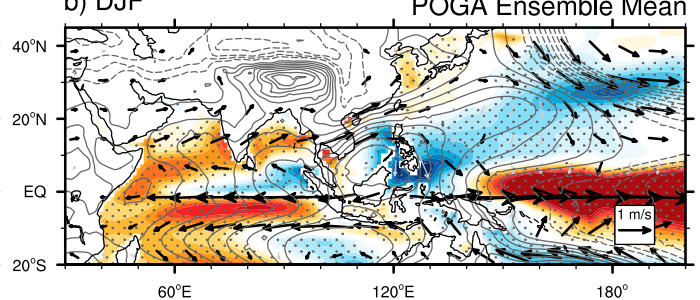

d) MAM

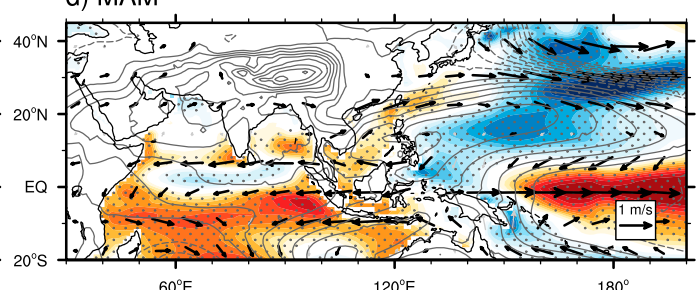

f) JJA

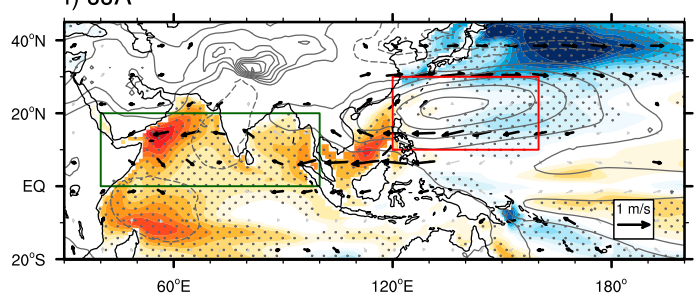

$0.12 \quad 0.24 \quad 0.36$

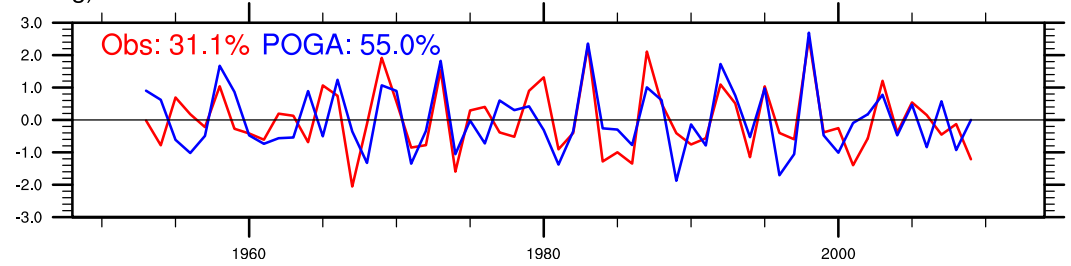

FIG. 4. Structure of the IPOC mode represented by the regression coefficients of SST (shading; K), 850-hPa wind velocity (arrows), and SLP (contours with interval of $0.1 \mathrm{hPa}$; zero line omitted) against (g) the normalized PC1 of NWP SLP in (left) observations and (right) the POGA ensemble mean in (a),(b) the preceding DJF and the concurrent (c),(d) MAM and (e),(f) JJA. See section 3 for details of the EOF analysis. SST and winds whose correlation exceeds the 0.01 significance level based on a Student's $t$ test are stippled and thickened, respectively.

observations and the ensemble mean, respectively. The POGA ensemble mean successfully captures key coupled processes of the IPOC, specifically, the IO and NWP responses.

\section{ENSO-forced and internal variability}

The POGA ensemble mean only includes ENSOforced variability (if the ensemble size is sufficient) while both ENSO-forced and internal variabilities are important in individual POGA runs and observations. We project NWP SLP variability in each realization onto the spatial pattern of the seasonally stratified EOF1 for the POGA ensemble mean to obtain a projected time series (PT). The correlation coefficients among the ensemble members show large variations (Fig. 6), ranging from 0.39 to 0.71 , due to internal variability. We have also computed the correlation between the POGA PTs and the observed PC1. The coefficients are slightly lower than among POGA members. All correlation coefficients $\left[r\left(\mathrm{PT}_{\mathrm{POGA}}, \mathrm{PC}_{\mathrm{obs}}\right)\right]$ are above a 0.01 confidence level except for run 1 (at 0.21 , slightly below the 0.1 confidence level). We have also projected observed SLP variability onto the POGA ensemble mean EOF1. Interestingly, the projected coefficient is more highly correlated with POGA individual runs on the basis of the POGA ensemble mean EOF than based on observed EOF. This may be associated with model bias in simulating the ENSO forced pattern. Alternatively, this may suggest that the observed EOF pattern is "contaminated" by internal variability. This section discusses how the internal and ENSO-forced variability together 

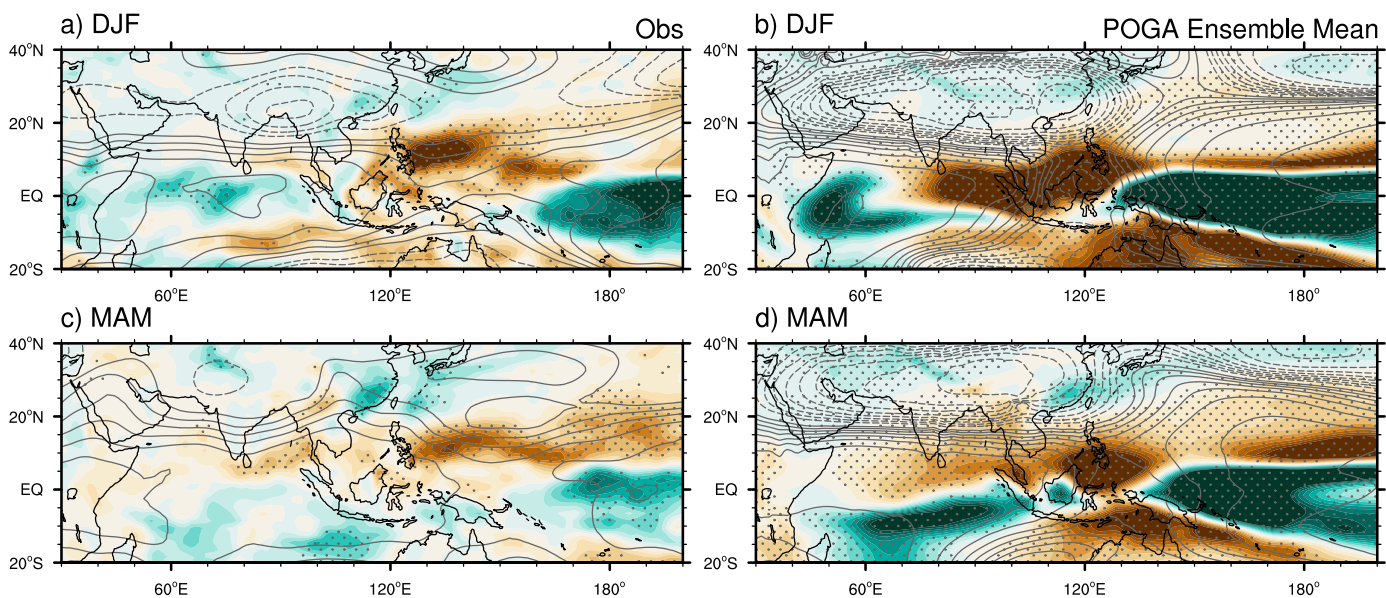

d) MAM
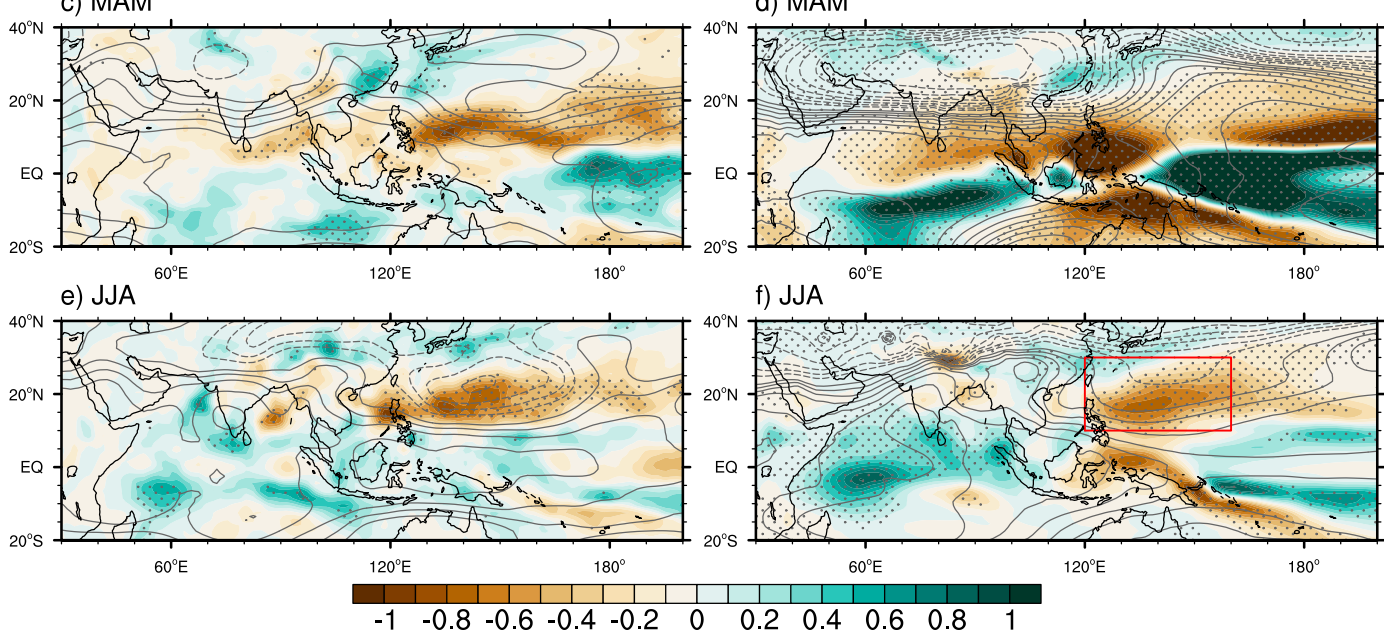

FIG. 5. As in Fig. 3, but for the regression coefficients of precipitation (shading; $\mathrm{mm} \mathrm{day}^{-1}$ ) and correlation coefficients of tropospheric temperatures (contours with interval of 0.1 ; zero line omitted). Precipitation values whose correlation exceeds the 0.01 significance level based on a Student's $t$ test are stippled.

contribute to Indo-western Pacific summer climate variability.

\section{a. Local indices}

Figure 7 compares three regional indices between the POGA and observations in JJA: NIO SST averaged over $0^{\circ}-20^{\circ} \mathrm{N}, 40^{\circ}-100^{\circ} \mathrm{E}$ (green box in Fig. 4f), NWP SLP, and precipitation indices averaged over $10^{\circ}-30^{\circ} \mathrm{N}$, $120^{\circ}-160^{\circ} \mathrm{E}$ (red boxes in Figs. $4 \mathrm{f}$ and $5 \mathrm{f}$ ). Those regions are chosen to capture the largest anomalies in this season. We focus on the summer season as the IPOC has a significant impact on the East Asia summer monsoon (e.g., Huang and Wu 1989; Chang et al. 2000). The POGA ensemble mean indices follow observations quite well. The correlation coefficients between the POGA ensemble mean and the observations are 0.74 , 0.43 , and 0.45 , respectively, all exceeding the 0.01 significance level based on a Student's $t$ test. POGA also captures the close relationship between ENSO and the IPOC mode as the indices are highly correlated with the preceding NDJ Niño-3.4 index, at 0.92, 0.59, and -0.67 for NIO SST, NWP SLP, and NWP precipitation, respectively. We can further estimate the ENSO effect as the ratio of ensemble mean interannual variance to the total interannual variance in individual runs. The averaged percentages of the ENSO effect on summer (JJA)
NIO SST, NWP SLP, and NWP precipitation for 18712014 are $57 \%, 37 \%$, and $34 \%$, respectively. Thus, internal variability contributes to a large portion of the total summer Indo-western Pacific variability.

We compute the intermember standard deviation of each index in the JJA(1) season among the POGA ensemble members for each calendar year. The intermember standard deviation shows some year-to-year variations (not shown), but it is not significantly correlated with the preceding NDJ or concurrent JJA Niño3.4 SST. This indicates that summer internal variability is independent of ENSO phase. Figure 8a shows the probability distribution function of the Niño-3.4 index for 1871-2014 (the first and last 5 years are excluded due to the high-pass filtering). The index shows a skewed distribution (positive in 58 years and negative in 75 years), consistent with previous findings (Okumura and Deser 2010; Okumura et al. 2011). There are more extreme El Niños (Niño-3.4 SST anomaly $>2 \mathrm{~K}$ ) than La Niñas (Niño-3.4 SST anomaly $<-2 \mathrm{~K}$ ). We compute the averaged intermember standard deviations of the three regional indices and bin the results according to the preceding NDJ Niño-3.4 index (Fig. 8b). The averaged intermember standard deviations of the NWP SLP, precipitation, and NIO SST are around $0.5 \mathrm{hPa}, 0.5 \mathrm{~mm}$ day $^{-1}$, and $0.1 \mathrm{~K}$, respectively. These measures of internal 


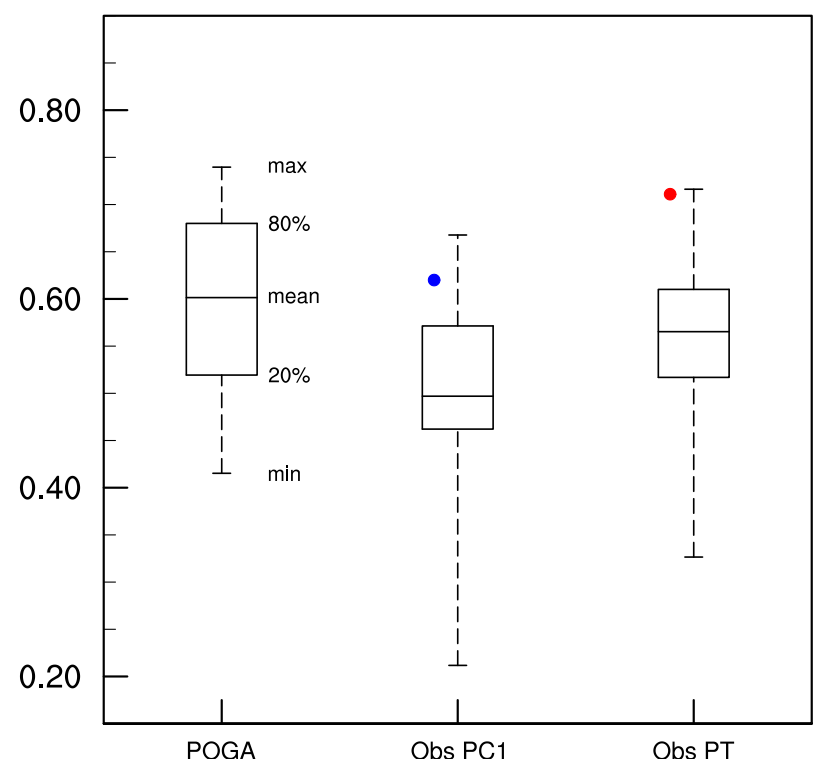

FIG. 6. Box-and-whisker plots of the correlation coefficients among the projection coefficients (PT) in the POGA experiment (labeled as POGA), POGA PT with observed PC1 (Obs PC1), and POGA PT with observed PT (Obs PT). Blue and red dots denote the correlation coefficients of observed PC1 and PT with the ensemble mean PC1, respectively.

variance are generally not affected by the ENSO phase or amplitude, although it is possible that ENSO phase-induced background change may modulate internal variability (Wu and Kirtman 2006). Following $\mathrm{Wu}$ and Kirtman (2006), we have done a similar analysis for the $\operatorname{DJF}(0 / 1)$ precipitation over $5^{\circ}-15^{\circ} \mathrm{N}$, $120^{\circ}-130^{\circ} \mathrm{E}$ and the results are similar to those in summer (not shown).

The summer NWP SLP index is significantly correlated with Niño-3.4 SST in the preceding winter. We then extract the internal SLP variability in summer NWP using a linear regression model: $\mathrm{SLP}=a P+\mathrm{SLP}^{\prime}$, where $P$ is the preceding NDJ Niño-3.4 index, $a$ denotes the SLP regression coefficient against the Niño-3.4 index, and the residual SLP $^{\prime}$ is due to the internal variability. This $\mathrm{SLP}^{\prime}$ index does not significantly correlate with the concurrent Niño-3.4 SST $(-0.01)$ but does moderately correlate with the Niño-4 SST $(-0.21$, slightly below the 0.1 confidence level). Figure 9 shows the distribution of the JJA(1) correlation coefficient of SST, SLP, 850-hPa winds, precipitation, and TT against SLP' $^{\prime}$. The anomalous high pressure accompanied with AAC is located over the NWP, with cold SST on its southeast flank and over the central equatorial Pacific (Fan et al. 2013; Chen et al. 2016). This pattern is somewhat similar to the ENSO-forced IPOC, but SST anomalies over the IO are significantly weaker. The same analysis has been applied to the individual POGA runs. The spatial patterns are very similar to the observational results, except that SST anomalies are more robust in the SCS, Bay of Bengal, and coastal Arabian Sea (Fig. 9b). In fact, the SST anomalies are robust and resemble the pattern in POGA individual runs after the 1970s regime shift (not shown), which may be related to the low-frequency background change in the IO. The decadal shift may also be related to the linear regression approach used to extract the internal variability as ENSO shows strong asymmetry between the positive and negative phases not only in amplitude but also in spatiotemporal distributions (Fig. 8; Okumura and Deser 2010; Okumura et al. 2011).

Another approach to extract the internal variability with POGA is to examine the intermember spread. Spatial patterns are obtained by regressing against the SLP index in the POGA intermember spread. The results (Fig. 9c) are almost identical to those for POGA individual runs and observations, justifying the regression-based approach and confirming the crucial role of the internal variability in summer NWP climate. SST anomalies in the western IO, including the Arabian Sea and the SWIO, are weak no matter what approach is used to extract the internal variability. The difference in the spatial distribution (Figs. 4e,f vs Fig. 9) between the ENSO-forced and internal IPOC may suggests that remote SWIO forcing plays a less dominant role than local air-sea coupling in the internal IPOC. Robust SST anomalies in the NWP, SCS, and Bay of Bengal indicate that the regional air-sea interactions may be important for ENSO-unrelated internal variabilities, consistent with the IPOC effect of Kosaka et al. (2013) and Xie et al. (2016). The differences may indicate ENSO's role in synchronizing the evolution of the IO warming and the NWP AAC.

\section{b. Decadal modulations}

Figure 10 compares 25 -yr running correlation of the NIO SST (averaged over $40^{\circ}-100^{\circ} \mathrm{E}, 0^{\circ}-20^{\circ} \mathrm{N}$ ) with the NDJ(0/1) Niño-3.4 index in the ERSST, the ensemble mean, and one typical realization of POGA. The observed correlation shows strong decadal modulations, in both amplitude and timing of the peak season (Fig. 10c). The winter SST correlation coefficients are high before the 1930s and after the 1960s while low in between, following the modulations of ENSO magnitude (Fig. 10d). Summer SST correlations are especially high after the 1990s, consistent with previous studies (Chowdary et al. 2012). In the POGA ensemble mean, the decadal modulation of the correlation coefficients is weak in the El Niño decay summer (Fig. 10a). The IO SST shows strong double-peak patterns throughout the analyzed period, with high correlations located on the peak winter $(0 / 1)$ and 

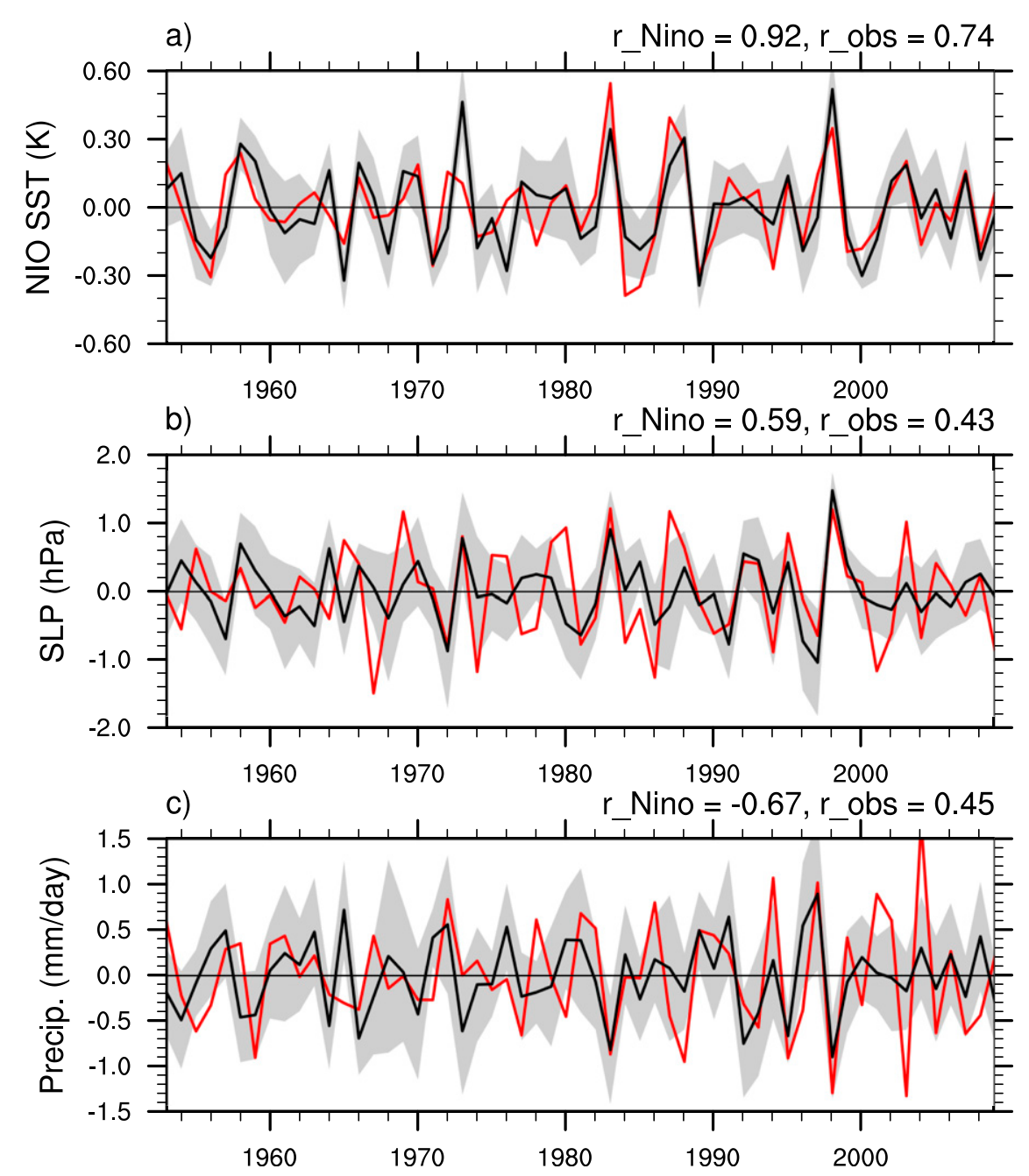

FIG. 7. Ensemble mean (black curves) and intermember standard deviations (shading) of the (a) NIO SST, (b) NWP SLP, and (c) NWP precipitation in JJA in POGA. Correlations of the ensemble-mean indices with the preceding Niño-3.4 index ( $\mathrm{r} \_$Nino) and observational indices ( $\left.r \_o b s\right)$ are indicated at the top of each panel. Red curves are the indices from the observations.

decay summer (1) of ENSO. Relatively low correlation is observed in $\operatorname{DJF}(0 / 1)$ after 1980 when the ENSO amplitude is strong, which may be related to the strong ENSO-induced bias in the NIO (section 3; Fig. 2b). We have also checked individual POGA runs. In the individual run, the timing of the maximum correlation is close to the ensemble mean, but the magnitude of the correlation is strongly modulated (Fig. 10b). Other runs show similar modulations with apparently random phase. Typically, the 25-yr running correlation of JJA(1) NIO SST in individual runs can range from $\sim 0.4$ to $\sim 0.9$, compared to the narrow range of $0.83-0.95$ in the ensemble mean.

The decadal modulation of the NIO SST-ENSO correlation can be explained by the linear interference between internal and ENSO-forced variability.
Consider a linear regression model of the IO SST anomaly in JJA(1), $T=a P+\varepsilon$, where $P$ is the $\mathrm{NDJ}(0 / 1)$ Niño-3.4 index, $a$ is the regression coefficient, and $\varepsilon$ is internal variability. The correlation coefficient between the Niño-3.4 index and NIO SST $[r(T, P)]$ is given by

$$
\begin{aligned}
r(T, P) & =\frac{E[(a P+\varepsilon)(P)]}{\sqrt{\sigma_{T}^{2}} \sqrt{\sigma_{P}^{2}}} \\
& =\frac{E\left[\left(a P^{2}\right)\right]+E[(\varepsilon P)]}{\sqrt{E\left(a^{2} P^{2}\right)+2 a E(\varepsilon P)+E\left(\varepsilon^{2}\right)} \sqrt{E\left(P^{2}\right)}}
\end{aligned}
$$

where $E$ denotes the mathematical expectation, and $\sigma_{P}$ and $\sigma_{T}$ represent the standard deviation of the Niño-3.4 index and NIO SST, respectively. The 25-yr running correlation can be estimated with ensemble-mean Niño-3.4 

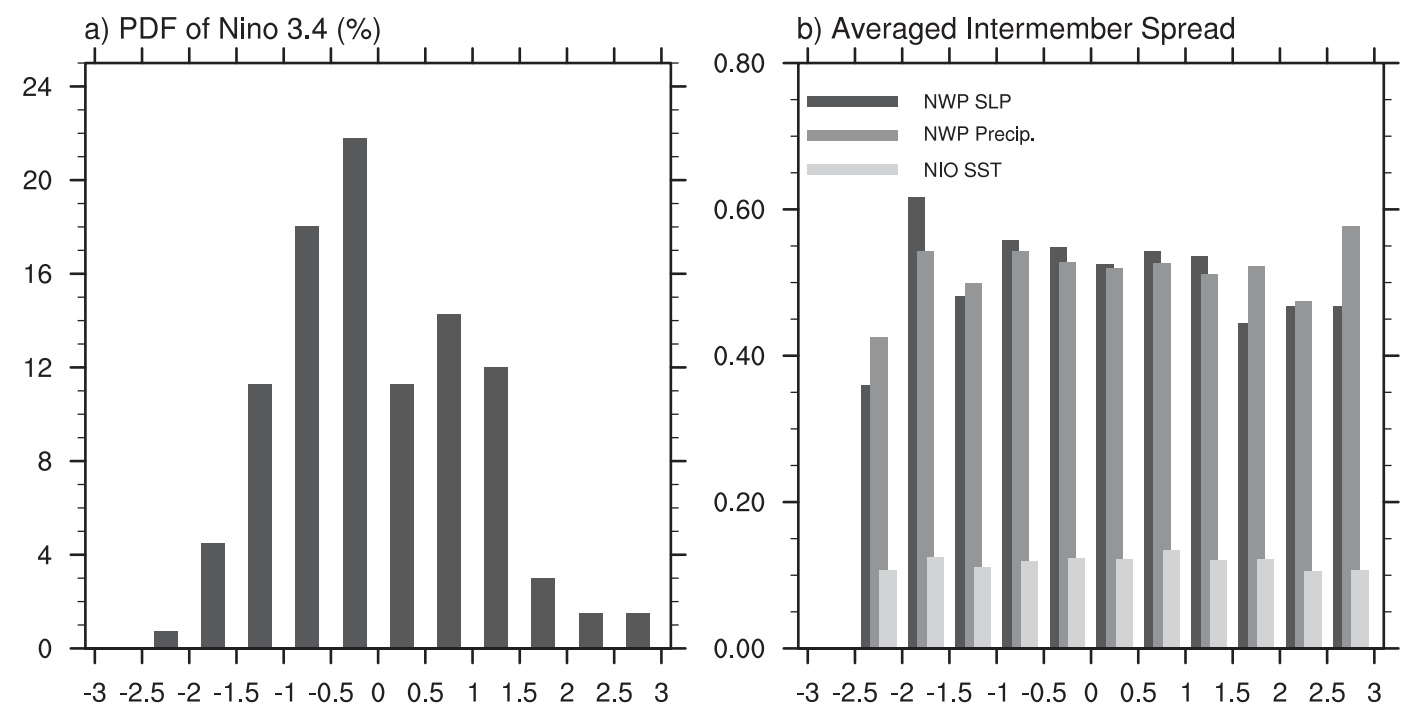

FIG. 8. (a) Histogram of the NDJ(0/1) Niño-3.4 index probability density function and (b) averaged standard deviation of JJA(1) NIO SST (K), NWP SLP (hPa), and NWP precipitation (mm day ${ }^{-1}$ ) with respect to the NDJ(0/1) Niño-3.4 index.

index, the internal variability of the IO SST, and their covariance in each realization. If the internal variability is not correlated with the Niño-3.4 index [i.e. $E(\varepsilon P)=0$ ], Eq. (1) can be further simplified as

$$
r(T, P)=\frac{1}{\sqrt{1+\frac{\sigma_{\varepsilon}^{2}}{a^{2} \sigma_{P}^{2}}}},
$$

with $\sigma_{\varepsilon}$ representing the standard deviation of internal NIO SST variability. The correlation coefficient is then simply a function of the amplitude ratio between noise and the Niño-3.4 index. For a finite window of 25 years, however, the covariance between Niño-3.4 and NIO SST is generally nonzero.

In the ensemble mean, the internal variability is suppressed, and $\sigma_{\varepsilon}^{2}$ is small. As a result, the correlation coefficient is close to 1 and varies only slightly with ENSO amplitude in summer. In individual runs, on the other hand, the internal variability is comparable to the ENSO-forced variability (Fig. 10d). The correlation coefficients are then determined by the relative amplitude and covariance between ENSO-forced and internal variability [Eq. (1)]. This can also, to some extent, explain the random peaking phase of the ENSO correlation in observations. As discussed in the previous sections, the ENSO effect on NIO SST is overestimated in $\operatorname{DJF}(0 / 1)$ and JJA(1) but underestimated in MAM(1) in POGA (Figs. 1 and 2), resulting in insignificant MAM(1) correlations in the POGA runs.

The ENSO-AAC correlation also displays similar decadal modulations. Figure 11 shows the 25 -yr running correlation of JJA(1) NIO SST, NWP SLP, and NWP precipitation with the NDJ(0/1) Niño-3.4 index in all 10 members. The ensemble average of the correlation shows strong decadal variations with considerable spread among members. The 10 -member averaged correlation coefficient is modulated by the ENSO amplitude. The large spread in the correlation among ensemble members is due to the interference by the internal variability [Eq. (1)]. The decadal evolution of the correlation can differ somewhat among individual runs as the internal variability is random in phase and amplitude, but the correlation tends to be high during the epochs of high ENSO variance, lending support to the hypothesis that ENSO amplitude modulates IPOC correlation with ENSO (e.g., Chowdary et al. 2012; Kubota et al. 2016).

POGA overestimates the ENSO-forced effect on the NIO SST in JJA(1) and NWP precipitation based on the regression coefficient $a$ by $15 \%$, and 9\%, respectively, while underestimating the effect on NWP SLP by $11 \%$. The 25-yr running correlation between ENSO and regional indices is due to both the ENSO amplitude and random internal variability. Large (small) ENSO forcing could lead to a weak (strong) decadal modulation of 25-yr running correlations compared to observations.

\section{Summary with discussion}

We have evaluated the skill of the POGA experiment in simulating the IPOC mode in post-ENSO seasons, specifically the basinwide IO warming and NWP AAC. The POGA ensemble mean successfully simulates the 

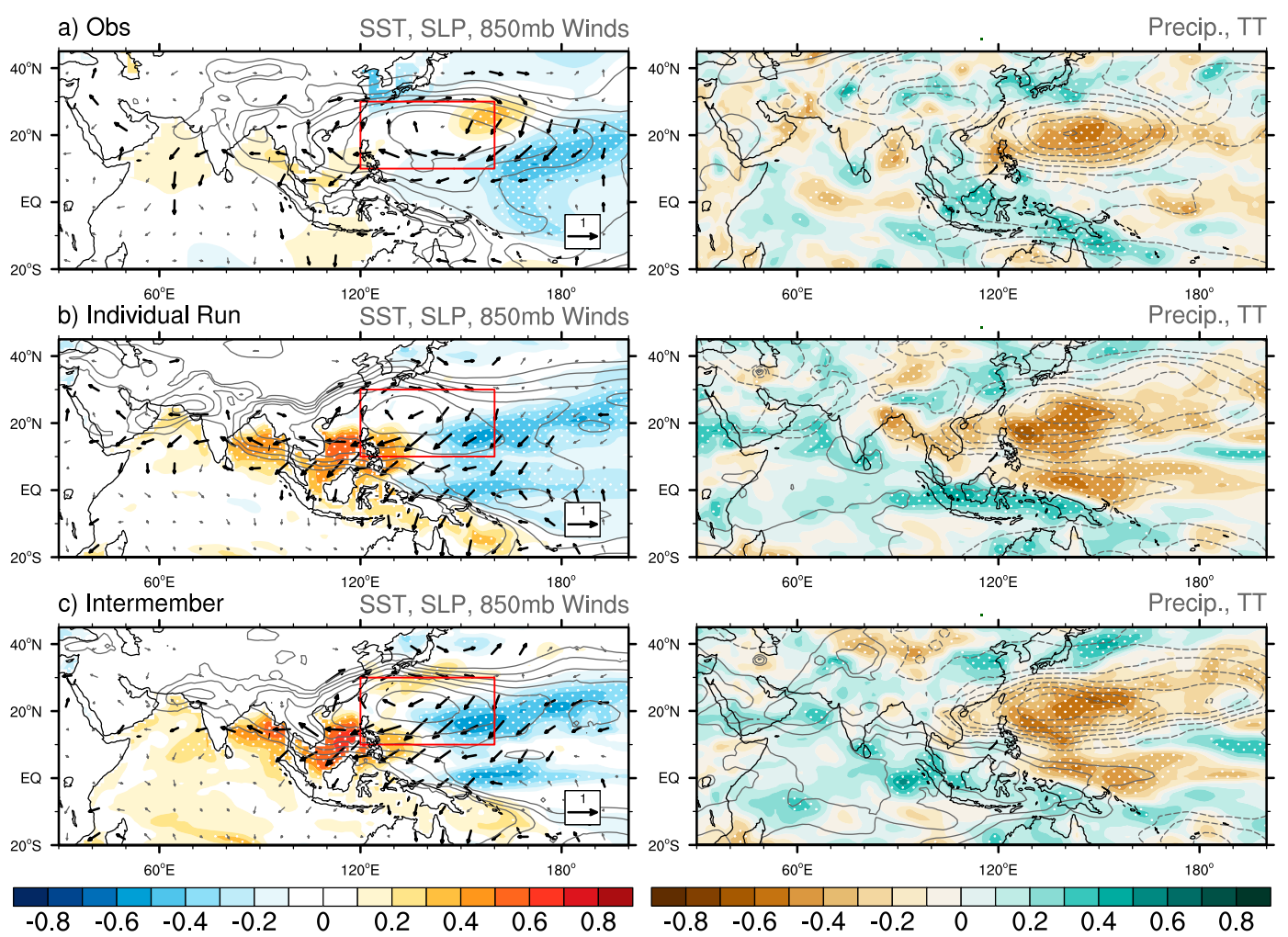

$-0.8-0.6 \quad-0.4 \quad-0.2$

FIG. 9. Structure of internal variability associated with JJA(1) NWP SLP' (averaged in the red box) in (a) observations and (b) an individual POGA run, represented by correlation coefficients of (left) SLP (contours with interval of 0.1; zero line omitted), SST (shading), and 850-hPa winds (arrows) and (right) precipitation (shading) and tropospheric temperature (contours with interval of 0.1 ; zero line omitted) with $\mathrm{SLP}^{\prime}$ averaged over the NWP $\left(120^{\circ}-\right.$ $160^{\circ} \mathrm{E}, 10^{\circ}-30^{\circ} \mathrm{N}$; red boxes in the left panels). Stippling and thickened arrows indicate that the correlations shown by shadings and arrows are significant at the 0.05 level, respectively. (c) As in (a),(b), but for correlations with NWP SLP averaged in the POGA intermember spread.

warming of the tropical IO with slightly stronger amplitude. The IO warming persists for two seasons after the peak of El Niño. Key features to maintain the SST anomalies are captured by the POGA such as the westward propagation of the oceanic Rossby wave over the south tropical IO and the antisymmetrical wind anomalies over the equatorial IO in MAM(1). Over the tropical NWP, the POGA ensemble mean simulates the evolution of the AAC in post-El Niño seasons. The AAC is coupled with negative SST anomalies over its southeast flank in winter and spring and with positive SST in the IO in summer. The correlation coefficient between the NIO SST and NWP AAC is high in both POGA and observations, suggesting the regional coupled mode. POGA shows some biases such as the absence of the SST warming in the SCS in the El Niño winter and a westward shifted AAC. These biases may be related to the cold tongue bias in CM2.1. The location bias of the AAC is alleviated in the following summer when the AAC is anchored by the warm IO SST.
We have also investigated possible interactions between ENSO-forced and internal variability in the Indowestern Pacific regions. In the POGA experiment, the ENSO-forced variability contributes $57 \%, 37 \%$, and $34 \%$ of the total variance for summer variability in NIO SST, NWP SLP, and NWP precipitation, respectively. The local indices show large spread among POGA members due to internal variability. Thus, the AAC includes both the ENSO-forced and internal variability, and the latter can be isolated in the POGA ensemble. We show that the spatial pattern of internal AAC variability is similar between observations and POGA. Specifically, there are negative SST anomalies on the southeast flank of the AAC where the background wind is easterly, while SST anomalies are positive over the NIO and SCS where the background wind is westerly. These SST anomalies and AAC are suggested to be coupled to form the regional IPOC mode (Kosaka et al. 2013, Xie et al. 2016). In contrast, SWIO SST anomalies are absent from the internal variability. 
a) Ensemble Mean

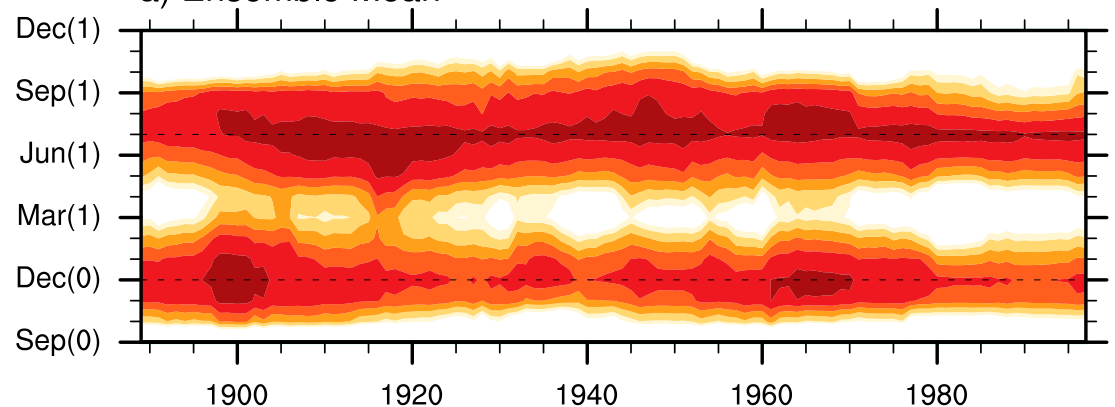

b) Run 1

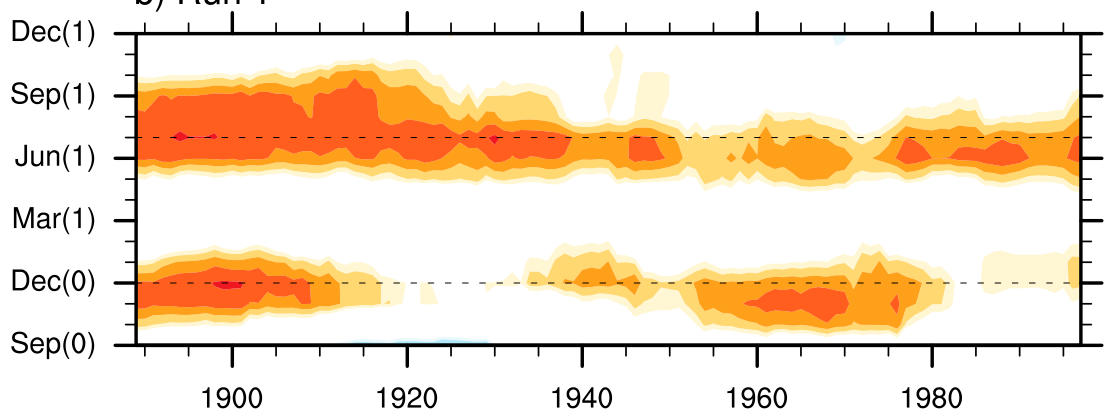

c) Obs

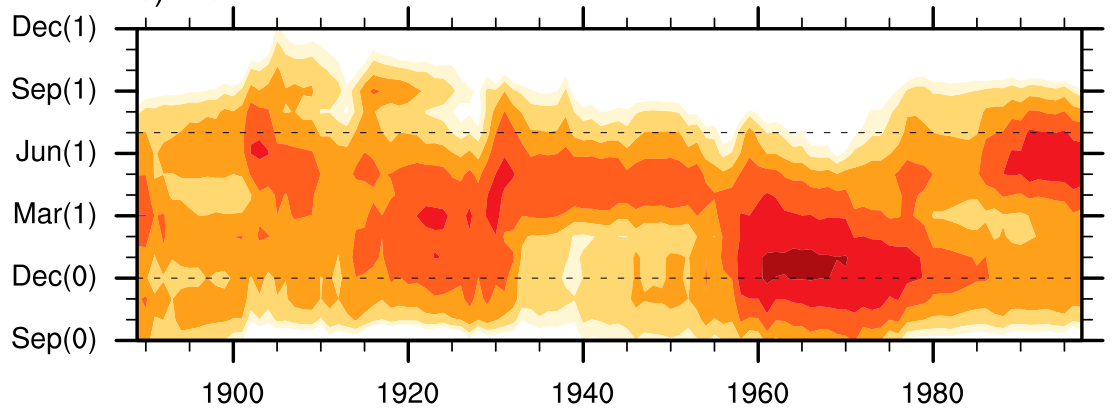

d) Running std.

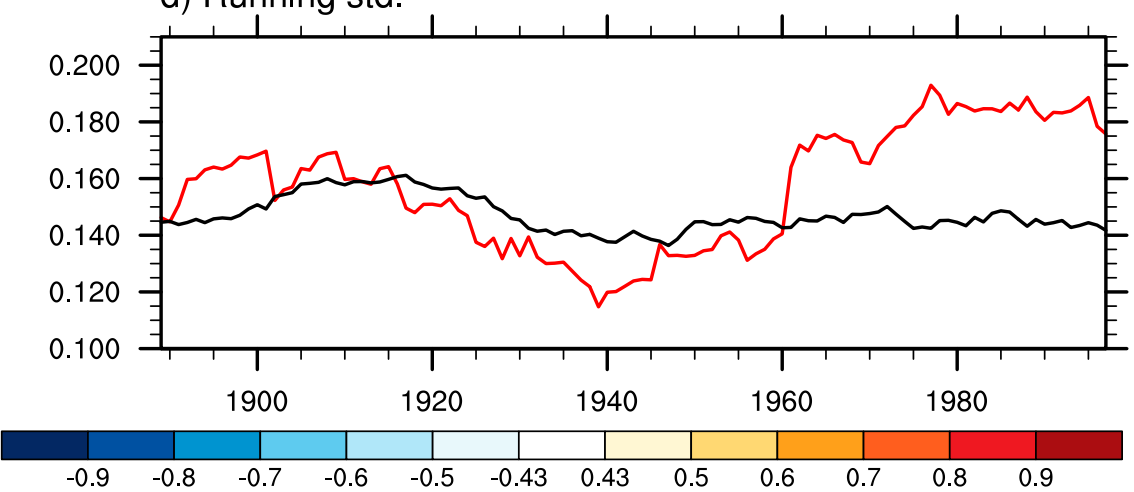

FIG. 10. The 25-yr running correlation coefficient between the seasonal NIO SST and NDJ(0/1) Niño-3.4 index for (a) the POGA ensemble mean, (b) one POGA realization (run 1), and (c) observations. (d) The 25-yr running standard deviation (K) of the NDJ(0/1) Niño-3.4 index scaled by regression coefficient $a$ (red curve) estimated with POGA ensemble mean and 10-member averaged internal NIO SST variability (black curve) in JJA(1). Years on the $x$ axis denote the center of the sliding window. 


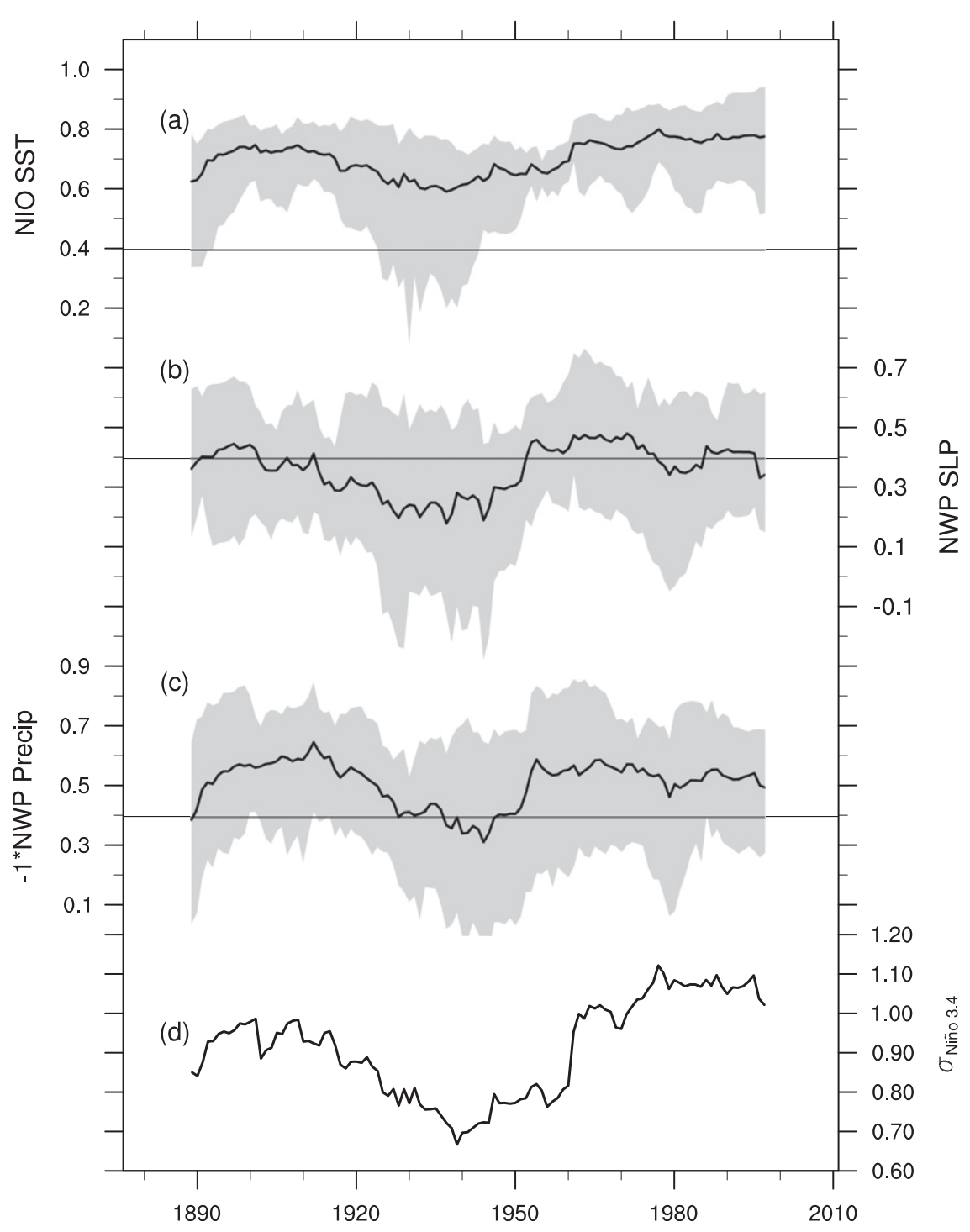

FIG. 11. The 25-yr running correlations of JJA(1) (a) NIO SST, (b) NWP SLP, and (c) signflipped NWP precipitation against the NDJ(0/1) Niño-3.4 index, calculated for individual members of POGA. Lines indicate the ensemble mean of the correlations (after the Fisher $z$ transformation) whereas shadings denote the ensemble maximum and minimum. (d) The 25-yr running standard deviation of the Niño-3.4 index (K). Years on the $x$ axis denote the center of the sliding window.

The ENSO teleconnection to the Indo-western Pacific region shows strong decadal variations in observations and individual POGA realizations. We show that such decadal modulations are weak in the POGA ensemble mean where internal variability is suppressed. Internal variability is random in phase with apparent decadal variation in amplitude in both observations and individual POGA realizations. Interference between the internal variability and ENSO amplitude modulates the decadal correlation between ENSO and Indo-western Pacific variability.
Our approaches to separate ENSO-forced and ENSOunrelated internal variability in POGA are based on the linear assumption. Wu and Kirtman (2006) suggest that ENSO affects seasonal mean precipitation and hence the amplitude of the ENSO-unrelated variability. Our study shows that in the ENSO decay summer [JJA(1)], the amplitude of internal variability does not change significantly with ENSO amplitude or phase (Fig. 8). This lends support to our hypothesis that the impact of the nonlinear interaction between ENSO-forced and internal variability is weak in that season. The reason for the 
discrepancy between our results and $\mathrm{Wu}$ and Kirtman (2006) needs further investigation.

Background state change on other time scales may also be important for Indo-western Pacific climate variability. Nonlinear interactions between ENSO and the annual cycle are an example (Stuecker et al. 2015; Wu et al. 2017a,b). The interactions are captured by the POGA ensemble mean as every member shares the same seasonal cycle and ENSO evolution. In this study, a high-pass filter is applied to remove low-frequency variability as we focus on the interannual variability in this study. Low-frequency variability may still introduce nonlinear effect on the IPOC by altering background state (Chen et al. 2014; Hu et al. 2014; Song and Zhou 2015). While the POGA ensemble mean can capture the external forcings, the interaction with other natural variability such as the interdecadal Pacific oscillation or Atlantic multidecadal oscillation is a topic for future research.

Acknowledgments. We sincerely thank the three anonymous reviewers for the constructive comments and suggestions. This work is supported by the Natural Science Foundation of China (41490640 and 41490641), China Scholarship Council (201606330006), U.S. National Science Foundation (AGS 1637450), Japanese Ministry of Education, Culture, Sports, Science and Technology (the "Integrated Research Program for Advancing Climate Models" and "Arctic Challenge for Sustainability"), the Japan Society for the Promotion of Science (15H05466 and 18H01278), and the Japan Science and Technology Agency (Belmont Forum CRA "InterDec").

\section{REFERENCES}

Alexander, M. A., I. Bladé, M. Newman, J. R. Lanzante, N.-C. Lau, and J. D. Scott, 2002: The atmospheric bridge: The influence of ENSO teleconnections on air-sea interaction over the global oceans. J. Climate, 15, 2205-2231, https://doi.org/10.1175/15200442(2002)015<2205:TABTIO>2.0.CO;2.

Bellenger, H., É. Guilyardi, J. Leloup, M. Lengaigne, and J. Vialard, 2014: ENSO representation in climate models: From CMIP3 to CMIP5. Climate Dyn., 42, 1999-2018, https:// doi.org/10.1007/s00382-013-1783-z.

Chakravorty, S., J. S. Chowdary, and C. Gnanaseelan, 2013: Spring asymmetric mode in the tropical Indian Ocean: Role of El Niño and IOD. Climate Dyn., 40, 1467-1481, https://doi.org/ 10.1007/s00382-012-1340-1.

Chang, C.-P., Y.-S. Zhang, and T. Li, 2000: Interannual and interdecadal variations of the East Asian summer monsoon and tropical Pacific SSTs. Part I: Roles of the subtropical ridge. J. Climate, 13, 4310-4325, https://doi.org/10.1175/15200442(2000)013<4310:IAIVOT $>2.0$.CO;2.

Chen, W., R. Lu, and B. Dong, 2014: Intensified anticyclonic anomaly over the western North Pacific during El Niño decaying summer under a weakened Atlantic thermohaline circulation. J. Geophys. Res. Atmos., 119, 13 637-13 650, https:// doi.org/10.1002/2014JD022199.

Chen, Z., Z. Wen, R. Wu, X. Lin, and J. Wang, 2016: Relative importance of tropical SST anomalies in maintaining the western North Pacific anomalous anticyclone during El Niño to La Niña transition years. Climate Dyn., 46, 1027-1041, https://doi.org/10.1007/s00382-015-2630-1.

Chowdary, J. S., C. Gnanaseelan, and S.-P. Xie, 2009: Westward propagation of barrier layer formation in the 2006-07 Rossby wave event over the tropical southwest Indian Ocean. Geophys. Res. Lett., 36, L04607, https://doi.org/ 10.1029/2008GL036642.

, S.-P. Xie, H. Tokinaga, Y. M. Okumura, H. Kubota, N. Johnson, and X.-T. Zheng, 2012: Interdecadal variations in ENSO teleconnection to the Indo-western Pacific for 1870-2007. J. Climate, 25, 1722-1744, https://doi.org/10.1175/ JCLI-D-11-00070.1.

Delworth, T. L., and Coauthors, 2006: GFDL's CM2 global coupled climate models. Part I: Formulation and simulation characteristics. J. Climate, 19, 643-674, https://doi.org/10.1175/ JCLI3629.1.

Du, Y., S.-P. Xie, G. Huang, and K. Hu, 2009: Role of air-sea interaction in the long persistence of El Niño-induced north Indian Ocean warming. J. Climate, 22, 2023-2038, https://doi.org/ 10.1175/2008JCLI2590.1.

_ , S. Xie, Y. Yang, X. Zheng, L. Liu, and G. Huang, 2013: Indian Ocean variability in the CMIP5 multimodel ensemble: The basin mode. J. Climate, 26, 7240-7266, https://doi.org/10.1175/ JCLI-D-12-00678.1.

Fan, L., S.-I. Shin, Q. Liu, and Z. Liu, 2013: Relative importance of tropical SST anomalies in forcing East Asian summer monsoon circulation. Geophys. Res. Lett., 40, 2471-2477, https:// doi.org/10.1002/grl.50494.

Giese, B. S., and S. Ray, 2011: El Niño variability in Simple Ocean Data Assimilation (SODA), 1871-2008. J. Geophys. Res., 116, C02024, https://doi.org/10.1029/2010JC006695.

Gill, A. E., 1980: Some simple solutions for heat-induced tropical circulation. Quart. J. Roy. Meteor. Soc., 106, 447-462, https:// doi.org/10.1002/qj.49710644905.

Hu, K., G. Huang, X.-T. Zheng, S.-P. Xie, X. Qu, Y. Du, and L. Liu, 2014: Interdecadal variations in ENSO influences on northwest Pacific-East Asian early summertime climate simulated in CMIP5 models. J. Climate, 27, 5982-5998, https://doi.org/ 10.1175/JCLI-D-13-00268.1.

Huang, B.-H., and J. Shukla, 2007a: Mechanisms for the interannual variability in the tropical Indian Ocean. Part I: The role of remote forcing from the tropical Pacific. J. Climate, 20, 2917-2936, https://doi.org/10.1175/JCLI4151.1.

, and _ 2007b: Mechanisms for the interannual variability in the tropical Indian Ocean. Part II: Regional processes. J. Climate, 20, 2937-2960, https://doi.org/10.1175/JCLI4169.1.

Huang, B.-Y., and Coauthors, 2015: Extended Reconstructed Sea Surface Temperature version 4 (ERSST.v4). Part I: Upgrades and intercomparisons. J. Climate, 28, 911-930, https://doi.org/ 10.1175/JCLI-D-14-00006.1.

Huang, G., K. Hu, and S.-P. Xie, 2010: Strengthening of tropical Indian Ocean teleconnection to the northwest Pacific since the mid-1970s: An atmospheric GCM study. J. Climate, 23, 52945304, https://doi.org/10.1175/2010JCLI3577.1.

Huang, R. H., and Y. F. Wu, 1989: The influence of ENSO on the summer climate change in China and its mechanism. $A d v$. Atmos. Sci., 6, 21-32, https://doi.org/10.1007/BF02656915. 
Izumo, T., C. B. Boyer Montégut, J.-J. Luo, S. K. Behera, S. Masson, and T. Yamagata, 2008: The role of the western Arabian Sea upwelling in Indian monsoon rainfall variability. J. Climate, 21, 5603-5623, https://doi.org/10.1175/ 2008JCLI2158.1.

Kalnay, E., and Coauthors, 1996: The NCEP/NCAR 40-Year Reanalysis Project. Bull. Amer. Meteor. Soc., 77, 437-471, https://doi.org/10.1175/1520-0477(1996)077<0437:TNYRP> 2.0.CO;2.

Kamae, Y., X. Li, S.-P. Xie, and H. Ueda, 2017: Atlantic effects on recent decadal trends in global monsoon. Climate Dyn., 49, 3443-3455, https://doi.org/10.1007/s00382-017-3522-3.

Klein, S. A., B. J. Soden, and N.-C. Lau, 1999: Remote sea surface temperature variations during ENSO: Evidence for a tropical atmospheric bridge. J. Climate, 12, 917-932, https://doi.org/ 10.1175/1520-0442(1999)012<0917:RSSTVD>2.0.CO;2.

Kosaka, Y., and H. Nakamura, 2006: Structure and dynamics of the summertime Pacific-Japan teleconnection pattern. Quart. J. Roy. Meteor. Soc., 132, 2009-2030, https://doi.org/10.1256/ qj.05.204.

— equatorial Pacific surface cooling. Nature, 501, 403-407, https://doi.org/10.1038/nature12534.

—_ and _ 2016: The tropical Pacific as a key pacemaker of the variable rates of global warming. Nat. Geosci., 9, 669-673, https://doi.org/10.1038/ngeo2770.

,,-- N.-C. Lau, and G. A. Vecchi, 2013: Origin of seasonal predictability for summer climate over the northwestern Pacific. Proc. Natl. Acad. Sci. USA, 110, 7574-7579, https://doi.org/ 10.1073/pnas.1215582110.

Kubota, H., Y. Kosaka, and S.-P. Xie, 2016: A 117-year long index of the Pacific-Japan pattern with application to interdecadal variability. Int. J. Climatol., 36, 1575-1589, https://doi.org/ 10.1002/joc.4441.

Lau, N.-C., and M. J. Nath, 2000: Impact of ENSO on the variability of the Asian-Australian monsoons as simulated in GCM experiments. J. Climate, 13, 4287-4309, https://doi.org/ 10.1175/1520-0442(2000)013<4287:IOEOTV > 2.0.CO;2.

$\longrightarrow$, and 2003: Atmosphere-ocean variations in the IndoPacific sector during ENSO episodes. J. Climate, 16, 3-20, https://doi.org/10.1175/1520-0442(2003)016<0003:AOVITI > 2.0.CO;2.

Li, G., and S.-P. Xie, 2014: Tropical biases in CMIP5 multimodel ensemble: The excessive equatorial Pacific cold tongue and double ITCZ problems. J. Climate, 27, 1765-1780, https://doi.org/ 10.1175/JCLI-D-13-00337.1.

Li, T., B. Wang, B. Wu, T. Zhou, C.-P. Chang, and R. Zhang, 2017: Theories on formation of an anomalous anticyclone in western North Pacific during El Niño: A review. J. Meteor. Res., 31, 987-1006, https://doi.org/10.1007/s13351-017-7147-6.

Liu, Z., and M. Alexander, 2007: Atmospheric bridge, oceanic tunnel, and global climatic teleconnections. Rev. Geophys., $\mathbf{4 5}$, RG2005, https://doi.org/10.1029/2005RG000172.

Masumoto, Y., and G. Meyers, 1998: Forced Rossby waves in the southern tropical Indian Ocean. J. Geophys. Res., 103, 27 589-27 602, https://doi.org/10.1029/98JC02546.

Matsuno, T., 1966: Quasi-geostrophic motions in the equatorial area. J. Meteor. Soc. Japan, 44, 25-43, https://doi.org/10.2151/ jmsj1965.44.1_25.

Nigam, S., and H.-S. Shen, 1993: Structure of oceanic and atmospheric low-frequency variability over the tropical Pacific and Indian Oceans. Part I: COADS observations. J. Climate, 6,
657-676, https://doi.org/10.1175/1520-0442(1993)006<0657: SOOAAL $>2.0 . \mathrm{CO} ; 2$.

Nitta, T., 1986: Long-term variations of cloud amount in the western Pacific region. J. Meteor. Soc. Japan, 64, 373-390, https://doi.org/10.2151/jmsj1965.64.3_373.

Okumura, Y. M., and C. Deser, 2010: Asymmetry in the duration of El Niño and La Niña. J. Climate, 23, 5826-5843, https://doi.org/ 10.1175/2010JCLI3592.1.

—, M. Ohba, C. Deser, and H. Ueda, 2011: A proposed mechanism for the asymmetric duration of El Niño and La Niña. J. Climate, 24, 3822-3829, https://doi.org/10.1175/ 2011JCLI3999.1.

Perigaud, C., and P. Delecluse, 1993: Interannual sea level variations in the tropical Indian Ocean from Geosat and shallow water simulations. J. Phys. Oceanogr., 23, 1916-1934, https://doi.org/10.1175/1520-0485(1993)023<1916:ISLVIT>2.0.CO;2.

Schott, F. A., S.-P. Xie, and J. P. McCreary Jr., 2009: Indian Ocean circulation and climate variability. Rev. Geophys., 47, RG1002, https://doi.org/10.1029/2007RG000245.

Song, F., and T. Zhou, 2015: The crucial role of internal variability in modulating the decadal variation of the East Asian summer monsoon-ENSO relationship during the twentieth century. J. Climate, 28, 7093-7107, https://doi.org/10.1175/ JCLI-D-14-00783.1.

Stuecker, M.-F., F.-F. Jin, A. Timmermann, and S. McGregor, 2015: Combination mode dynamics of the anomalous northwest Pacific anticyclone. J. Climate, 28, 1093-1111, https://doi.org/ 10.1175/JCLI-D-14-00225.1.

Terao, T., and T. Kubota, 2005: East-west SST contrast over the tropical oceans and the post El Niño western North Pacific summer monsoon. Geophys. Res. Lett., 32, L15706, https:// doi.org/10.1029/2005GL023010.

Tokinaga, H., S.-P. Xie, A. Timmermann, S. McGregor, T. Ogata, H. Kubota, and Y. M. Okumura, 2012: Regional patterns of tropical Indo-Pacific climate change: Evidence of the Walker circulation weakening. J. Climate, 25, 1689-1710, https://doi.org/ 10.1175/JCLI-D-11-00263.1.

Wang, B., R. Wu, and X. Fu, 2000: Pacific-East Asian teleconnection: How does ENSO affect East Asian climate? J. Climate, 13, 1517-1536, https://doi.org/10.1175/15200442(2000)013<1517:PEATHD>2.0.CO;2.

,$- \ldots$, and T. Li, 2003: Atmosphere-warm ocean interaction and its impacts on Asian-Australian monsoon variation. J. Climate, 16, 1195-1211, https://doi.org/10.1175/15200442(2003)16<1195:AOIAII > 2.0.CO;2.

_ J. Yang, T. Zhou, and B. Wang, 2008: Interdecadal changes in the major modes of Asian-Australian monsoon variability: Strengthening relationship with ENSO since the late 1970s. J. Climate, 21, 1771-1789, https://doi.org/10.1175/ 2007JCLI1981.1.

_ J. Li, and Q. He, 2017: Variable and robust East Asian monsoon rainfall response to El Niño over the past 60 years (1957-2016). Adv. Atmos. Sci., 34, 1235-1248, https://doi.org/ 10.1007/s00376-017-7016-3.

Wu, B., T. Zhou, and T. Li, 2017a: Atmospheric dynamic and thermodynamic processes driving the western North Pacific anomalous anticyclone during El Niño. Part I: Maintenance mechanisms. J. Climate, 30, 9621-9635, https://doi.org/10.1175/ JCLI-D-16-0489.1.

_ - - and,$- 2017 \mathrm{~b}$ : Atmospheric dynamic and thermodynamic processes driving the western North Pacific anomalous anticyclone during El Niño. Part II: Formation 
processes. J. Climate, 30, 9637-9650, https://doi.org/10.1175/ JCLI-D-16-0495.1.

Wu, R., and B. Wang, 2002: A contrast of the East Asian summer monsoon-ENSO relationship between 1962-77 and 1978-93. J. Climate, 15, 3266-3279, https://doi.org/10.1175/15200442(2002)015<3266:ACOTEA > 2.0.CO;2.

— , and B.P. Kirtman, 2006: Changes in spread and predictability associated with ENSO in an ensemble Coupled GCM. J. Climate, 19, 4378-4396, https://doi.org/10.1175/JCLI3872.1.

— Ocean asymmetric mode in boreal spring. J. Geophys. Res., 115, D08101, https://doi.org/10.1029/2009JD012999.

_ Z. Hu, and B. P. Kirtman, 2003: Evolution of ENSO-related rainfall anomalies in East Asia. J. Climate, 16, 3742-3758, https://doi.org/10.1175/1520-0442(2003)016<3742:EOERAI $>$ 2.0.CO;2.

_ J. L. Kinter, and B. P. Kirtman, 2005: Discrepancy of interdecadal changes in the Asian region among the NCEP-NCAR reanalysis, objective analyses, and observations. J. Climate, 18, 3048-3067, https://doi.org/10.1175/JCLI3465.1.

_- B. P. Kirtman, and V. Krishnamurthy, 2008: An asymmetric mode of tropical Indian Ocean rainfall variability in boreal spring. J. Geophys. Res., 113, D05104, https://doi.org/10.1029/ 2007JD009316.

— W. When, G. Wang, and K. Hu, 2014: Relative contribution of ENSO and East Asian winter monsoon to the South China Sea SST anomalies during ENSO decaying years. J. Geophys. Res. Atmos., 119, 5046-5064, https://doi.org/10.1002/2013JD021095.

Xie, S.-P., and Z.-Q. Zhou, 2017: Seasonal modulations of El Niñorelated atmospheric variability: Indo-western Pacific Ocean feedback. J. Climate, 30, 3461-3472, https://doi.org/10.1175/ JCLI-D-16-0713.1.
, H. Annamalai, F. A. Schott, and J. P. McCreary Jr., 2002: Structure and mechanisms of south Indian Ocean climate variability. J. Climate, 15, 864-878, https://doi.org/10.1175/ 1520-0442(2002)015<0864:SAMOSI $>2.0 . C O ; 2$.

, K. Hu, J. Hafner, H. Tokinaga, Y. Du, G. Huang, and T. Sampe, 2009: Indian Ocean capacitor effect on Indowestern Pacific climate during the summer following El Niño. J. Climate, 22, 730-747, https://doi.org/10.1175/ 2008JCLI2544.1.

—, Y. Du, G. Huang, X. Zheng, H. Tokinaga, K. Hu, and Q. Liu, 2010: Decadal shift in El Niño influences on Indo-western Pacific and East Asian climate in the 1970s. J. Climate, 23, 3352-3368, https://doi.org/10.1175/2010JCLI3429.1.

-, Y. Kosaka, Y. Du, K. Hu, J. Chowdary, and G. Huang, 2016: Indo-western Pacific Ocean capacitor and coherent climate anomalies in post-ENSO summer: A review. Adv. Atmos. Sci., 33, 411-432, https://doi.org/10.1007/s00376-015-5192-6.

Yang, Y., S.-P. Xie, L. Wu, Y. Kosaka, N.-C. Lau, and G. A. Vecchi, 2015: Seasonality and predictability of the Indian Ocean dipole mode: ENSO forcing and internal variability. J. Climate, 28, 8021-8036, https://doi.org/10.1175/JCLI-D-15-0078.1.

,,,$----\longrightarrow$, and J. Li, 2017: ENSO forced and local variability of north tropical Atlantic SST: Model simulations and biases. Climate Dyn., https://doi.org/10.1007/s00382-0173679-9.

Zhang, R. H., A. Sumi, and M. Kimoto, 1996: Impact of El Niño on the East Asian monsoon: A diagnostic study of the ' $86 / 87$ and '91/92 events. J. Meteor. Soc. Japan, 74, 49-62, https://doi.org/ 10.2151/jmsj1965.74.1_49.

Zhou, Z.-Q., S.-P. Xie, G. J. Zhang, and W. Zhou, 2018: Evaluating AMIP skill in simulating interannual variability over the Indowestern Pacific. J. Climate, 31, 2253-2265, https://doi.org/ 10.1175/JCLI-D-17-0123.1. 